\title{
Self-Complementary AAV9 Gene Delivery Partially Corrects Pathology Associated with Juvenile Neuronal Ceroid Lipofuscinosis (CLN3)
}

\author{
Megan E. Bosch, ${ }^{1}$ Amy Aldrich, ${ }^{2}$ Rachel Fallet, ${ }^{2}$ Jessica Odvody, ${ }^{2}$ Maria Burkovetskaya, ${ }^{\circ}$ Kaitlyn Schuberth, ${ }^{1}$

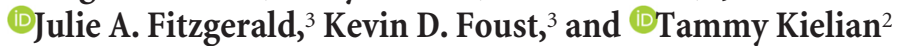 \\ ${ }^{1}$ Department of Pharmacology and Experimental Neuroscience, and ${ }^{2}$ Department of Pathology and Microbiology, University of Nebraska Medical Center, \\ Omaha, Nebraska 68198, and ${ }^{3}$ Department of Neuroscience, The Ohio State University, Columbus, Ohio 43210
}

Juvenile neuronal ceroid lipofuscinosis (JNCL) is a fatal lysosomal storage disease caused by autosomal-recessive mutations in CLN3 for which no treatment exists. Symptoms appear between 5 and 10 years of age, beginning with blindness and seizures, followed by progressive cognitive and motor decline and premature death (late teens to 20s). We explored a gene delivery approach for JNCL by generating two self-complementary adeno-associated virus 9 (scAAV9) constructs to address CLN3 dosage effects using the methyl-CpG-binding protein $2(\mathrm{MeCP} 2)$ and $\beta$-actin promoters to drive low versus high transgene expression, respectively. This approach was based on the expectation that low CLN3 levels are required for cellular homeostasis due to minimal CLN3 expression postnatally, although this had not yet been demonstrated in vivo. One-month-old $\mathrm{Cln} 3^{\Delta \mathrm{ex} 7 / 8}$ mice received one systemic (intravenous) injection of scAAV9/MeCP2-hCLN3 or scAAV9/ $\beta$-actin-hCLN3, with green fluorescent protein (GFP)-expressing viruses as controls. A promoter- dosage effect was observed in all brain regions examined, in which hCLN3 levels were elevated 3- to 8-fold in $\operatorname{Cln} 3^{\Delta \text { ex } 7 / 8}$ mice receiving scAAV9/ $\beta$-actin-hCLN3 versus scAAV9/MeCP2-hCLN3. However, a disconnect occurred between CLN3 levels and disease improvement, because only the scAAV9 construct driving low CLN3 expression (scAAV9/MeCP2-hCLN3) corrected motor deficits and attenuated microglial and astrocyte activation and lysosomal pathology. This may have resulted from preferential promoter usage because transgene expression after intravenous scAAV9/MeCP2-GFP injection was primarily detected in $\mathrm{NeuN}^{+}$neurons, whereas scAAV9/ $\beta$-actin-GFP drove transgene expression in $\mathrm{GFAP}^{+}$astrocytes. This is the first demonstration of a systemic delivery route to restore CLN3 in vivo using scAAV9 and highlights the importance of promoter selection for disease modification in juvenile animals.

Key words: AAV9; astrocyte; Batten disease; CLN3; lysosomal storage disease; microglia

\section{Significance Statement}

Juvenile neuronal ceroid lipofuscinosis (JNCL) is a fatal lysosomal storage disease caused by CLN3 mutations. We explored a gene delivery approach using two self-complementary adeno-associated virus 9 (scAAV9) constructs to address CLN3 dosage effects using the methyl-CpG-binding protein 2 (MeCP2) and $\beta$-actin promoters. hCLN3 levels were elevated 3- to 8 -fold in $\mathrm{Cln} 3^{\Delta \mathrm{ex} 7 / 8}$ mice receiving scAAV9/ $\beta$-actin-hCLN3 versus scAAV9/MeCP2-hCLN3 after a single systemic injection. However, only scAAV9/MeCP2hCLN3 corrected motor deficits and attenuated glial activation and lysosomal pathology. This may reflect preferential promoter usage because transgene expression with scAAV9/MeCP2-green fluorescent protein (GFP) was primarily in neurons, whereas scAAV9/ $\beta$-actin-GFP drove transgene expression in astrocytes. This is the first demonstration of systemic delivery for CLN3 using scAAV9 and highlights the importance of promoter selection for disease modification in juvenile animals.

\section{Introduction}

Juvenile neuronal ceroid lipofuscinosis (JNCL) is an autosomalrecessive lysosomal storage disease (LSD) occurring in 1 per

Received May 21, 2016; revised July 1, 2016; accepted July 29, 2016.

Author contributions: K.D.F. and T.K. designed research; M.E.B., A.A., R.F., J.O., M.B., K.S., and J.A.F. performed research; K.D.F. contributed unpublished reagents/analytic tools; M.E.B., A.A., M.B., K.S., K.D.F., and T.K. analyzed data; M.E.B. and T.K. wrote the paper.

This work was supported by the University of Nebraska Medical Center (Dean's Pediatric Research Fund Grant to T.K. and Graduate Fellowship to M.E.B.). T.K. received funding from Abeona Therapeutics for addi-
100,000 live births (Schultz et al., 2011). JNCL is caused by mutations in CLN3 that result in loss of protein expression (International Batten Disease Consortium, 1995). CLN3 encodes a

tional preclinical studies of scAAV9/MeCP2-hCLN3. We thank Dr. Fang Yu for assistance with statistical analysis and Dr. Nikolay Karpuk for designing the custom software used to quantitate immunofluorescent staining from confocal images.

The intellectual property for the scAAV9/hCLN3 constructs in JNCL by K.D.F. and T.K. (coinventors) has been licensed to Abeona Therapeutics. The remaining authors declare no competing financial interests. 
transmembrane protein primarily localized to the lysosome (Getty and Pearce, 2011); however, its function remains unknown (Kyttälä et al., 2006). JNCL is characterized by lysosomal inclusions composed of mitochondrial ATP synthase subunit C in addition to other proteins and lipids (Westlake et al., 1995). Despite the fact that disease symptoms are primarily neurologi$\mathrm{cal}$, there is no clear indication that lysosomal inclusions are directly responsible for neuron loss. This is because, although most neurons exhibit evidence of lysosomal storage, only certain neuron populations die (Haltia, 2003; Williams et al., 2006; Cotman and Staropoli, 2012; Cooper et al., 2015).

JNCL onset occurs between the ages of 5 and 10 years, presenting with rapid visual loss and seizures, progressive cognitive and motor decline (Aberg et al., 2000), and premature death by the late teens to 20s (Rakheja et al., 2007). Neurodegeneration occurs in the cortex, cerebellum, and subregions of the hippocampus (Autti et al., 1996; Tokola et al., 2014). Neuron loss has been reported in JNCL mouse models, but is relatively modest and not observed until late disease (i.e., 12-18 months), as opposed to early astrocyte and microglial activation (i.e., 1-3 months) (Pontikis et al., 2004; Burkovetskaya et al., 2014). There is no cure for JNCL and current therapeutics only manage disease symptoms; therefore, we examined the feasibility of gene delivery to restore normal CLN3 function. Gene therapy has shown promise in other LSDs that involve mutations in soluble enzymes, in part due to cross-correction of nontransduced cells (Passini et al., 2006; Macauley et al., 2012). The therapeutic bar is higher for JNCL because CLN3 encodes a transmembrane protein, presumably requiring more transduced cells to produce a phenotypic effect (Nugent et al., 2008).

Gene delivery via self-complementary adeno-associated virus 9 (scAAV9) has shown benefits in multiple neurodegenerative diseases, including spinal muscular atrophy and Rett syndrome (Gadalla et al., 2013; Garg et al., 2013; Meyer et al., 2015). AAV9 is an effective vector for CNS delivery after systemic (intravenous) injection because it crosses the blood-brain barrier and transduces both neuronal and non-neuronal cells (Foust et al., 2009). The scAAV9 genome is maintained as an episome in nondividing cells, with studies reporting transgene expression for years (Acland et al., 2005; Duqué et al., 2009). A prior study used a different AAV serotype (AAVrh.10/ $\beta$-actin-hCLN3) in neonatal $\mathrm{Cln} 3^{\Delta \mathrm{ex} 7 / 8}$ mice, which required multiple intracranial injections and limited biodistribution (Sondhi et al., 2014). In addition, $\mathrm{Cln} 3^{\Delta \mathrm{ex} 7 / 8}$ mice were treated at postnatal day 2 (P2) before disease-associated pathology manifested, and neither the identity of CNS transgene ${ }^{+}$cells nor behavioral assessments were performed (Sondhi et al., 2014). Our approach advances the field by using a systemic delivery route to enhance virus biodistribution and a promoter (methyl-CpG-binding protein 2; MeCP2) that preferentially drives transgene expression in neurons when administered to juvenile (i.e., 1-month-old) $C \ln 3^{\Delta \mathrm{ex} 7 / 8}$ mice, a time at which disease burden has already manifested.

Two scAAV9 constructs were generated to address CLN3 dosage effects in vivo; one driving low CLN3 expression with the $\mathrm{MeCP} 2$ promoter that showed efficacy in Rett syndrome (Garg et al., 2013) and a second driving high CLN3 levels via the chicken $\beta$-actin promoter. This approach was based on the expectation

Correspondence should be addressed to Tammy Kielian, Ph.D., University of Nebraska Medical Center, Department of Pathology and Microbiology, 985900 Nebraska Medical Center, Omaha, NE 68198-5900. E-mail: tkielian@unmc.edu.

DOI:10.1523/JNEUROSCI.1635-16.2016

Copyright $\odot 2016$ the authors $\quad 0270-6474 / 16 / 369670-14 \$ 15.00 / 0$ that low CLN3 levels are required for cellular homeostasis due to minimal postnatal CLN3 expression (Eliason et al., 2007), although this had not yet been demonstrated in vivo. One-monthold $\mathrm{Cln} 3^{\Delta \mathrm{ex} 7 / 8}$ mice received a single intravenous injection of scAAV9/ $\beta$-actin-hCLN3 or scAAV9/MeCP2-hCLN3, with green fluorescent protein (GFP)-expressing viruses as controls. Only the scAAV9 construct driving low CLN3 expression (scAAV9/ MeCP2-hCLN3) was capable of reducing motor deficits, glial activation, and lysosomal pathology in the $C \ln 3^{\Delta \mathrm{ex} 7 / 8}$ brain, whereas scAAV9/ $\beta$-actin-hCLN3 and GFP viruses had no benefit. This is the first demonstration of a systemic delivery route to restore CLN3 using scAAV9 and highlights the importance of promoter selection for modifying disease.

\section{Materials and Methods}

Animals. One-month-old male $\mathrm{Cln} 3^{\Delta \mathrm{ex} 7 / 8}$ mice (C57BL/6 background) lacking a $1.02 \mathrm{~kb}$ segment spanning exons 7 and 8 of CLN3 were used (Cotman et al., 2002). These mice harbor the same CLN3 deletion that occurs in $\sim 85 \%$ of mutated CLN3 alleles (International Batten Disease Consortium, 1995) and recapitulate many disease phenotypes, including motor deficits, glial activation, and progressive accumulation of lysosomal storage material (Cotman et al., 2002). Age-matched male C57BL/6 mice were used as WT controls (The Jackson Laboratory).

$A A V$ vector production and purification. ScAAV genomes were engineered to encode GFP or human CLN3 cDNA (NM_000086.2) under the control of the chicken- $\beta$-actin/cytomegalovirus hybrid promoter or the mouse minimal MeCP2 promoter (Adachi et al., 2005). Viral packaging was performed by SAB Technology. Briefly, viruses were packaged by standard triple transfection of helper, packaging (AAV2/9), and ITRcontaining plasmids into HEK293 cells. Vectors were purified by cesium chloride gradient centrifugation and titers were determined by silver staining.

In vivo administration of scAAV9 virus. One-month-old male WT and $\mathrm{Cln} 3^{\Delta \mathrm{ex} 7 / 8}$ mice ( $n=5-8 /$ group) were randomized into vehicle or virus treatment groups and received a single intravenous injection of $2 \times 10^{12}$ vg scAAV9/MeCP2-hCLN3, scAAV9/ $\beta$-actin-hCLN3, scAAV9/MeCP2GFP, or scAAV9/ $\beta$-actin-GFP or vehicle (PBS) via the retro-orbital sinus under isoflurane anesthesia. Body weights were recorded at weekly intervals throughout the study and blood chemistry analysis was conducted every 2 months after injection.

Accelerating rotarod. Motor activity of mice $(n=5-8 /$ group $)$ was monitored with an AccuRotor 4-Channel Rotarod (Omnitech Electronics) using a 3-cm-diameter rod (Lee et al., 2014). Mice were subjected to testing over 4 consecutive days with a training period in the A.M. and testing period in the P.M. that were separated by $2 \mathrm{~h}$. All trials were conducted during the same time of day for consistency. During the training period (one trial in the A.M.), mice were placed on the rotarod that was set to a constant speed of $4 \mathrm{rpm}$ for $5 \mathrm{~min}$. If animals fell during training, they were immediately returned to the rotating rod until the 5 min training was completed. For the testing period, the apparatus was set to accelerate from 0 to $40 \mathrm{rpm}$ over $5 \mathrm{~min}$. The rotation speed of $40 \mathrm{rpm}$ was maintained after the 5 min acceleration phase and the latency to fall was digitally recorded by the instrument. Each mouse was subjected to three P.M. trials daily with at least a 20 min rest between each run. Results are reported as the mean performance of each mouse over the $4 \mathrm{~d}$ testing period.

Immunofluorescence staining. Representative coronal brain sections were prepared from $\mathrm{Cln} 3^{\Delta \mathrm{ex} 7 / 8}$ mice receiving intravenous injections of scAAV9 constructs, as well as WT and $C \ln 3^{\Delta \text { ex } 7 / 8}$ vehicle-treated animals at 5 months after injection, as described previously with minor modifications (Burkovetskaya et al., 2014). Briefly, animals were deeply anesthetized using sodium pentobarbital and transcardially perfused with saline, followed by $4 \%$ paraformaldehyde (PFA). The brain was removed, postfixed in 4\% PFA overnight, and cryoprotected with 30\% sucrose overnight before embedding in optimal cutting temperature medium. Free-floating cryostat sections ( $30 \mu \mathrm{m}$; two tissue slices per brain region 

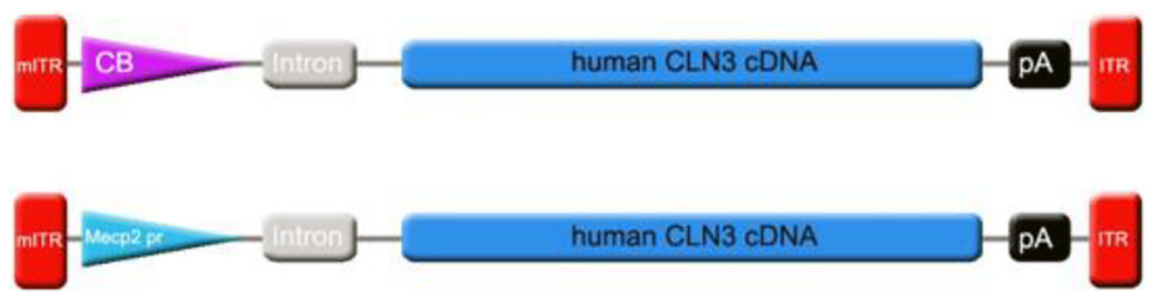

Figure 1. Self-complementary AAV9 constructs. Each construct contains identical minimal SV40 intron (gray), human CLN3 CDNA (blue), bovine growth hormone polyadenylation signals (black), and viral inverted terminal repeats (red) to package selfcomplementary virus. The first construct (top) contains the high-expressing chicken $\beta$-actin promoter (purple) and the second (bottom) contains the minimal essential promoter from the mouse MeCP2 gene (light blue).

per mouse) were prepared and slices containing the desired brain regions [somatosensory barrel field cortex (S1BF) and thalamus (TH)] were permeabilized by incubation in $0.1 \mathrm{M}$ PBS containing $0.3 \%$ Triton X-100 $(2 \times, 5$ min each). Tissues were then blocked with $10 \%$ donkey serum for $1 \mathrm{~h}$ at room temperature and incubated overnight at $4^{\circ} \mathrm{C}$ with primary antibodies, including a polyclonal rabbit anti-mitochondrial ATP synthase subunit C (kindly provided by Dr. Susan Cotman, Harvard Medical School), Iba-1 (1:200; BioCare Medical), NeuN (1:500; Abcam), GFAP (1:500, Dako, Carpinteria, CA); CD68 (1:200; Abcam), LAMP-1 (1:250; Abcam), or GFP (1:500; Abcam; incubated with tissues for $72 \mathrm{~h}$ ). After 3 washes with $1 \times$ PBS, brain sections were incubated with an appropriate biotin-streptavidin-conjugated secondary antibody and DAPI for nuclear identification. Autofluorescent inclusions in $\mathrm{Cln} 3^{\Delta \mathrm{ex} 7 / 8}$ tissues were quenched with a $70 \%$ solution of Sudan black for 10 min (Burkovetskaya et al., 2014) or TrueBlack according to the manufacturer's recommendations (Biotium). Immunofluorescence was visualized using a Carl Zeiss LSM 710 META confocal microscope with a $40 \times$ oil-immersion objective in a field-of-view of $450 \times 450 \mu \mathrm{m}(200 \times$ magnification $)$ or $225 \times$ $225 \mu \mathrm{m}$ (400× magnification). Tile images were acquired to visualize the entire S1BF $(810 \mu \mathrm{m} \times 1080 \mu \mathrm{m})$ or TH $(810 \mu \mathrm{m} \times 810 \mu \mathrm{m})$ for each section. For image quantification, $200 \mu \mathrm{m} \times 200 \mu \mathrm{m}$ nonoverlapping regions of interest (ROIs) were positioned throughout the S1BF (total of nine ROIs) and TH (total of six ROIs) using AxioVision software (Zeiss), whereupon total values from all ROIs were averaged for each slice. Individual slice averages per mouse were analyzed using SPSS to evaluate statistical significance using a mixed linear model approach. Results are reported as the mean intensity staining values (GFAP), area (CD68 and LAMP-1), or ROI count (SCMAS), as determined using a custom software program incorporating the Visual Basic function of AxioVision (Dr. Nikolay Karpuk, University of Nebraska Medical Center).

To quantify transgene expression in various CNS cell types, colocalization of transgene-positive cells $\left(\mathrm{GFP}^{+}\right)$with $\mathrm{NeuN}^{+}$neurons and $\mathrm{GFAP}^{+}$astrocytes was determined using the Imaris program (Bitplane). The Imaris auto-threshold colocalization function was used to determine nonrandom signal colocalization in the red and green channels (Costes et al., 2004). Next, settings were determined on a per-image basis and quantitative spot analysis (Banovic et al., 2010) was performed to determine the number of $\mathrm{GFP}^{+}, \mathrm{GFAP}^{+}$or $\mathrm{NeuN}^{+}$cells. Results are reported as the percentage of $\mathrm{GFP}^{+} \mathrm{NeuN}^{+}$ cells or $\mathrm{GFP}^{+} \mathrm{GFAP}^{+}$cells.

Western blot. Coronal sections (1200 $\mu \mathrm{m}$ thick) were prepared from acute brain slices using a vibratome while being bathed in ice-cold ACSF, whereupon the S1BF, striatum, visual cortex (VC), TH, cerebellum, and hippocampus were dissected to collect total protein extracts. Tissues were homogenized in cell lysis buffer containing $50 \mathrm{~mm}$ Tris- $\mathrm{HCl}, \mathrm{pH} 7.5$, $150 \mathrm{~mm}$ sodium chloride, $0.5 \%$ Triton X-100, 1 mm sodium orthovanadate, $10 \mathrm{~mm}$ sodium fluoride, and $0.5 \mathrm{~mm}$ phenylmethanesulfonyl fluoride supplemented with complete protease inhibitor (Roche) and phosphatase inhibitor (Thermo Scientific) tablets. Twenty micrograms of total protein was run on $10 \%$ PAGE gels, whereupon Western blotting was performed as described previously (Burkovetskaya et al., 2014). Blots were probed with anti-GFP (1:500; Abcam) and developed using chemiluminescence. Blots were stripped and reprobed with an antibody against $\beta$-actin (Abcam) to confirm uniformity in gel loading. Blots were quantitated by densitometry analysis using an Alpha Innotech imager (Protein Simple) with signals normalized to $\beta$-actin.

Quantitative PCR. Mice were perfused with PBS and brain regions dissected from vibratome sections as described above. RNA was isolated using TRI-zol reagent and treated with DNase I (Invitrogen) before cDNA conversion using an iScript cDNA synthesis kit (Bio-Rad). cDNA was used for real-time PCR with Applied Biosystems Gene Expression Master Mix and an Assays on Demand primer/probe set specific for exons 7-8 of human CLN3 (Hs01029238) and the housekeeping gene GAPDH. Relative expression of AAV9/ $\beta$-actin-hCLN3 was then calculated for each region relative to AAV9/MeCP2-hCLN3 after GAPDH normalization.

Statistical analysis. All assays were blinded thorough the entirety of data collection and analysis. Quantification of $\mathrm{GFP}^{+} \mathrm{NeuN}^{+}$or $\mathrm{GFP}^{+} \mathrm{GFAP}^{+}$cells was assessed in each brain region of interest and a Student's $t$ test was used to determine statistical significance between groups. For motor behavior analysis, results from all trials were averaged for each mouse in each treatment group and analyzed by repeatedmeasures ANOVA followed by a post hoc Tukey's test to compare experimental groups. Quantification of immunofluorescence staining was assessed using a mixed linear model in which the variables included group, animal, slice, and area or intensity of staining. Statistical significance between groups for each brain region was analyzed in SPSS software.

\section{Results}

\section{Generation of scAAV9/CLN3 constructs to assess CLN3 gene} dosage effects

Unlike other NCL forms with deficiencies in soluble lysosomal enzymes, CLN3 encodes a lysosomal transmembrane protein (International Batten Disease Consortium, 1995; Nugent et al., 2008; Getty and Pearce, 2011). Therefore, although enzyme replacement therapy trials are currently under way to treat lateinfantile neuronal ceroid lipofuscinosis (CLN2), in which restoration of enzyme function in a larger number of cells is thought to occur by cross-correction, this is not feasible for JNCL. Another issue in the field was the expectation that low CLN3 expression is required for cellular homeostasis. This was based on earlier studies with CLN3-lacZ reporter mice, which revealed limited CLN3 expression postnatally, as well as btn1 mutant yeast (CLN3 ortholog), in which overexpression was toxic (Pearce and Sherman, 1998; Eliason et al., 2007; Vitiello et al., 2010). However, a gene dosage effect for CLN3 has not yet been tested directly in vivo. To address this question, we generated two scAAV9 constructs, one driving low CLN3 expression with the MeCP2 promoter and a second driving high CLN3 levels via the chicken $\beta$-actin promoter (Fig. 1).

\section{Systemic administration of scAAV9 successfully crosses the blood-brain barrier to transduce neurons and astrocytes in juvenile $\mathrm{Cln} 3^{\Delta \text { ex7/8 }}$ mice}

In these studies, 1 -month-old $\mathrm{Cln} 3^{\Delta \mathrm{ex} 7 / 8}$ mice received a single intravenous injection of scAAV9/ $\beta$-actin-hCLN3, scAAV9/ MeCP2-hCLN3, or GFP constructs, with vehicle-treated WT and $\mathrm{Cln} 3^{\Delta \text { ex7/8 }}$ animals as controls. Virus administration was delayed to more accurately depict the age at which children are diagnosed with CLN3 disease (7-10 years) based on mouse-human age equivalent estimates (Geifman and Rubin, 2013) and when disease burden had already manifested. Throughout the 5-month 
A

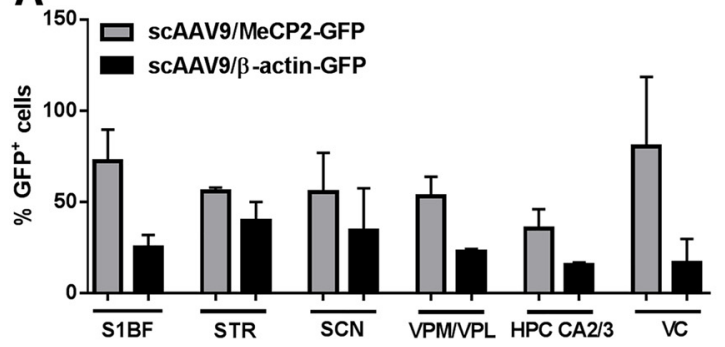

C

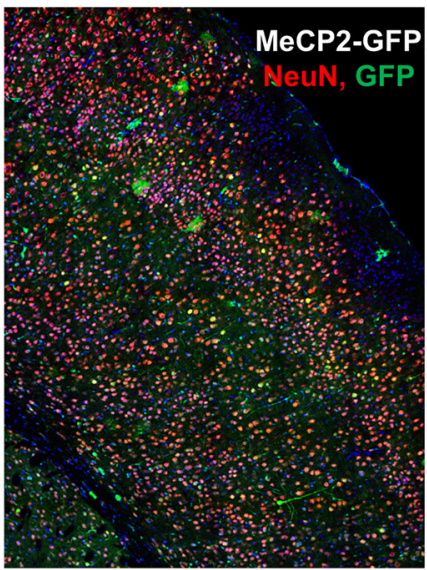

B
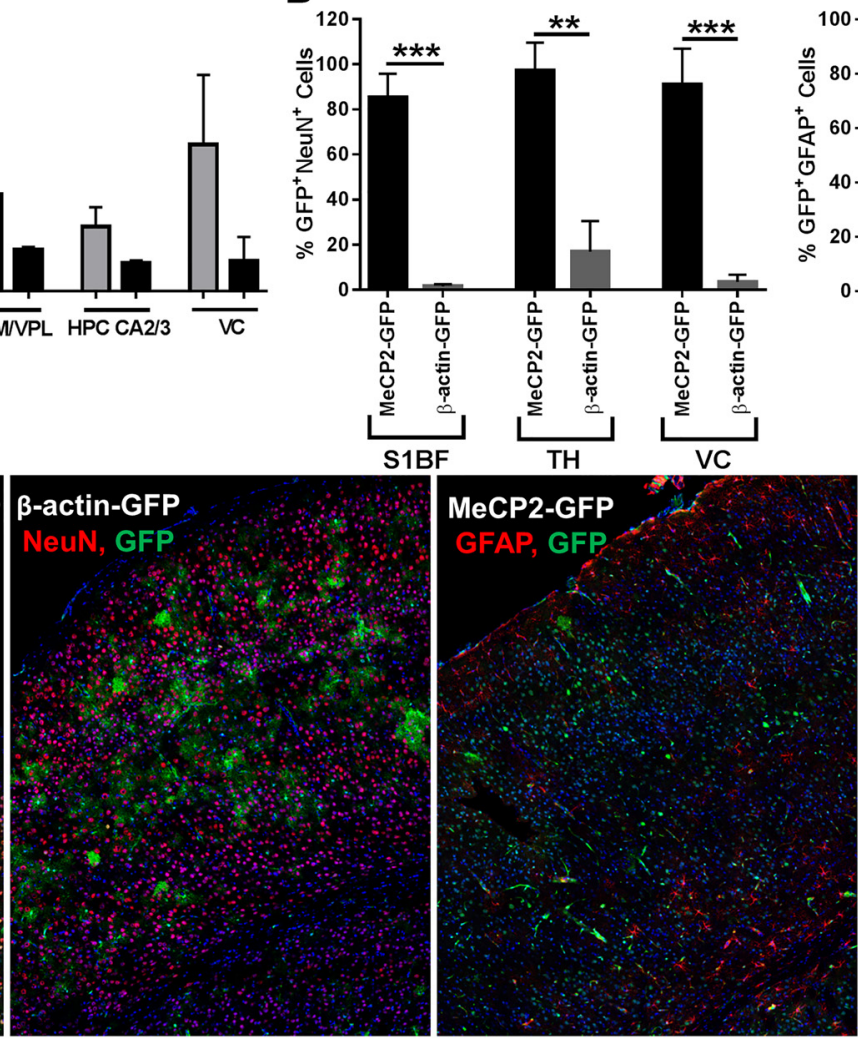
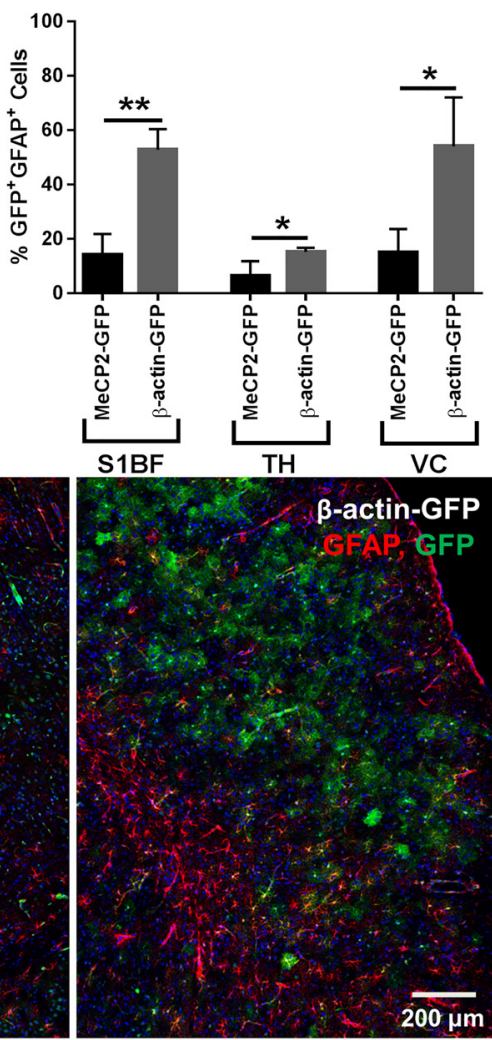

Figure 2. Comparative biodistribution of scAAV9 constructs in the $C \ln 3^{\Delta \text { ex } 7 / 8}$ brain after systemic delivery. One-month-old C $\ln 3^{\Delta \text { ex } 7 / 8}$ mice $(n=4-5 / g r o u p)$ received 1 intravenous injection of $2 \times 10^{12} \mathrm{vg}$ of scAAV9/MeCP2-GFP or scAAV9/ $\beta$-actin-GFP, whereupon animals were killed at 5 months after injection for analysis of virus biodistribution. $A$, Quantitation of total percentage GFP ${ }^{+}$ cells in the S1BF, striatum (STR), suprachiasmatic nucleus (SCN), thalamus (VPM/VPL), hippocampus (CA1/CA3), and VC. $\boldsymbol{B}$, Quantification of GFP $^{+}$neurons (NeuN ${ }^{+}$GFP ${ }^{+}$) and astrocytes $\left(\mathrm{GFAP}^{+} \mathrm{GFP}^{+}\right)$in the S1BF, TH, and VC of scAAV9/ $\beta$-actin-GFP vs scAAV9/MeCP2-GFP treated mice. $C$, Tiled $40 \times$ confocal images depicting preferential GFP expression in NeuN ${ }^{+}$neurons with scAAV9/MeCP2-GFP compared with scAAV9/ $\beta$-actin-GFP, with both constructs targeting astrocytes. Significant differences are denoted by asterisks $\left({ }^{*} p<0.05 ;{ }^{* *} p<0.01 ;{ }^{* * *} p<0.001\right.$ using a paired $t$ test).

study period, mice were weighed weekly and serum chemistry panels were performed every other month to assess potential toxicity. No significant changes in weight gain or serum chemistry profiles were observed throughout the study, nor was there any evidence of systemic inflammation as measured by the presence of serum cytokines/chemokines (data not shown). These findings demonstrate that the scAAV9 constructs did not induce toxicity or systemic inflammation, which is in agreement with prior reports using scAAV9 in both mice and nonhuman primates (Foust et al., 2013; Garg et al., 2013; Meyer et al., 2015).

scAAV has a limited packaging capacity (i.e., $2.2 \mathrm{~kb}$ ) (McCarty et al., 2001), which required CLN3 and GFP to be placed in separate viral constructs. In addition, this approach allowed virus biodistribution to be identified by GFP without interfering with CLN3 protein translation and function that could occur if a CLN3-GFP fusion construct was used. To assess scAAV9 biodistribution after a single intravenous injection of $\mathrm{Cln} 3^{\mathrm{ex} 7 / 8}$ mice with scAAV9/ $\beta$-actin-GFP or scAAV9/MeCP2-GFP, the percentage of $\mathrm{GFP}^{+}$cells and the specific cell types targeted was determined. Widespread GFP expression was observed with both the scAAV9/ $\beta$-actin-GFP and scAAV9/MeCP2-GFP constructs, with GFP detected throughout the brain, spinal cord, and eye (Figs. 2, 3). Interestingly, the percentage of $\mathrm{GFP}^{+}$cells in several brain regions of $\mathrm{Cln} 3^{\text {ex7/8 }}$ mice receiving scAAV9/MeCP2-GFP was higher at 5 months after injection compared with scAAV9/ $\beta$-actin-GFP (Fig. 2A). The scAAV9/MeCP2-GFP construct primarily drove GFP expression in $\mathrm{NeuN}^{+}$neurons $(>80 \%$ of
$\mathrm{GFP}^{+}$cells) in the $\mathrm{S} 1 \mathrm{BF}, \mathrm{TH}$, and VC with some $\mathrm{GFAP}^{+}$astrocytes ( $\leq 10 \%$ of $\mathrm{GFP}^{+}$cells) also observed (Fig. $2 B, C$ ). In contrast, scAAV9/ $\beta$-actin-GFP expression was more evident in astrocytes in the S1BF and VC (50-60\% of $\mathrm{GFP}^{+}$cells) compared with the scAAV9/MeCP2-GFP construct, although a few NeuN ${ }^{+}$neurons ( $\leq 16 \%$ of $\mathrm{GFP}^{+}$cells) were still detected with scAAV9/ $\beta$-actin-GFP (Fig. $2 B, C$ ). These regions were selected since they have been reported to display significant increases in early glial activation, as well as reduced neuron counts at advanced stages of disease (12-18 months) (Pontikis et al., 2005; Burkovetskaya et al., 2014). GFP expression was undetectable in microglia (data not shown), in agreement with previous reports showing that microglia are not permissive to AAV9-mediated transduction (Foust et al., 2009; Aschauer et al., 2013). We also found that primary microglia were recalcitrant to scAAV9 transduction in vitro, whereas primary astrocytes were receptive (data not shown), confirming our in vivo findings. Collectively, these results demonstrate that a single intravenous injection of scAAV9 results in extensive CNS transduction and that the $\mathrm{MeCP} 2$ promoter preferentially drives transgene expression in neurons in 1 -month-old mice, which does not occur with the $\beta$-actin construct. Because we were unable to measure hCLN3 protein expression directly due to the lack of specific antibodies combined with the limiting packaging size of scAAV9 vectors precluding the generation of a hCLN3/GFP bisictronic construct, it remains possible that hCLN3 biodistribution may differ slightly from GFP. However, because both the hCLN3 and GFP constructs 

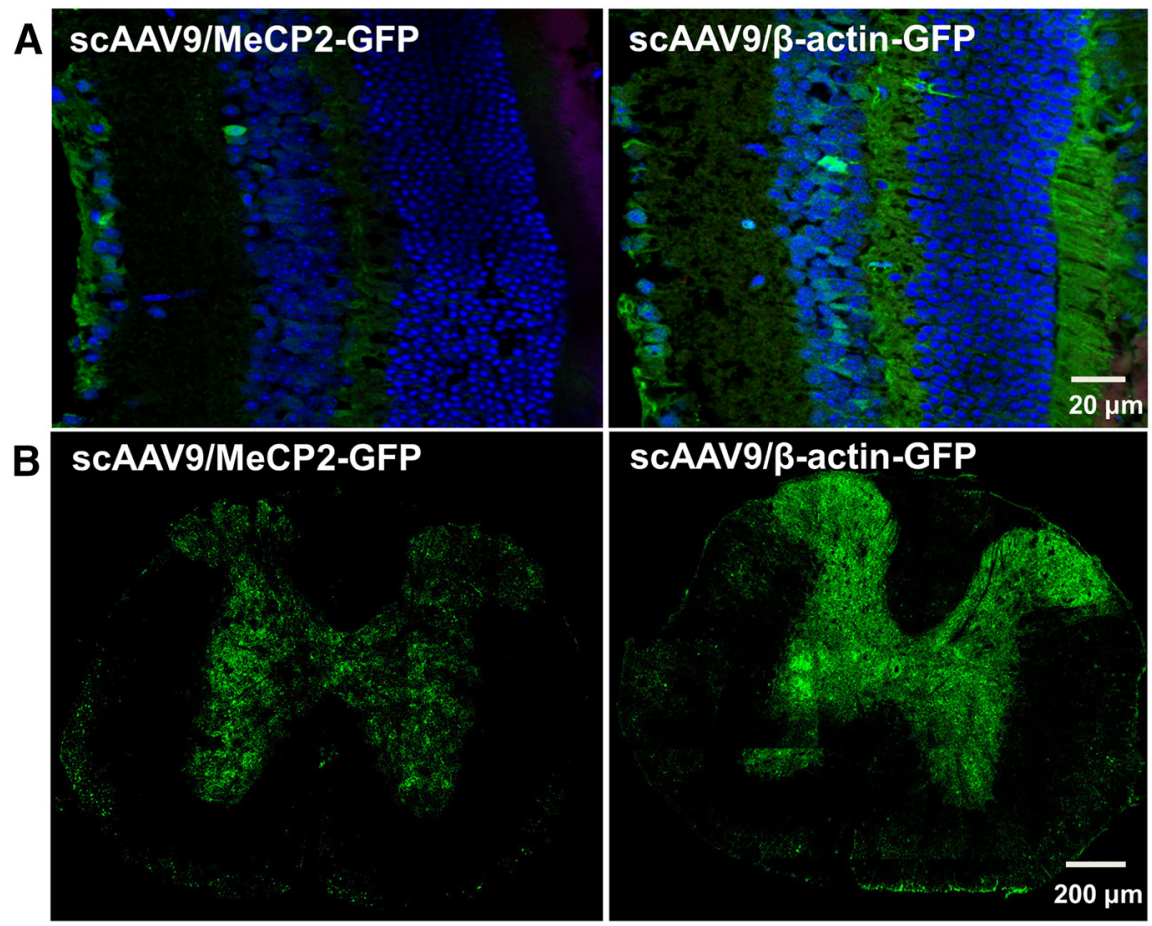

Figure 3. Intravenous scAAV9 delivery successfully transduces the spinal cord and eye. One-month-0ld $\ln 3^{\Delta \text { ex7/8 }}$ mice $(n=$ $4-5 /$ group) received 1 intravenous injection of $2 \times 10^{12} \mathrm{vg}$ of sCAAV9/MeCP2-GFP or scAAV9/ $\beta$-actin-GFP, whereupon animals were killed at 13 months after injection for analysis of virus biodistribution. Both scAAV9/ $\beta$-actin-GFP and scAAV9/MeCP2-GFP transduced multiple cells with in the eye $(\boldsymbol{A})$ and spinal cord $(\boldsymbol{B})$.

used an identical capsid (AAV9) and promoters, monitoring GFP expression as a readout for cells that would also be expressing hCLN3 represented the best available approach and represents a strategy that has been used in other studies (Foust et al., 2010; Bemelmans et al., 2013).

\section{$\mathrm{MeCP} 2$ and $\boldsymbol{\beta}$-actin promoters exhibit a gene dosage effect in vivo}

A current viewpoint in the JNCL field is that postnatal CLN3 expression should be maintained at low levels to support homeostasis, whereas overexpression of CLN3 may be toxic (Pearce and Sherman, 1998; Eliason et al., 2007; Vitiello et al., 2010). This is suggested by CLN3 reporter mice and yeast studies with the CLN3 ortholog btn1; however, to date, there is limited in vivo evidence to support this tenant. To investigate whether a promoter dosage effect was evident between the $\beta$-actin and MeCP2 constructs in vivo, Western blot analysis, immunofluorescence staining, and quantitative RT-PCR were conducted on multiple brain regions affected in JNCL. Western blot analysis confirmed that GFP expression driven by the $\beta$-actin promoter was up to 4 -fold higher compared with the MeCP2 promoter (Fig. 4A,B). This difference was also apparent in brain tissues using confocal microscopy, where images were collected using the same acquisition parameters (Fig. 4C). Quantitative PCR analysis revealed a 3 - to 8 -fold increase in hCLN3 expression driven by the scAAV9/ $\beta$-actin vs scAAV9/MeCP2 construct at 5 months after injection in several brain regions (Fig. 4D). hCLN3 protein expression could not be assessed because currently available antibodies exhibit nonspecific reactivity in both Western blots and immunostaining of brain tissues. hCLN3 mRNA expression was still detected at 13 months after injection, the latest time point examined (data not shown). This finding reflects episome stability, which is in agreement with other reports in which AAV9-driven transgene expression has been detected for years (Acland et al., 2005; Daya and Berns, 2008; Garg et al., 2013). These data support widespread scAAV9-mediated transgene expression throughout the CNS after a single intravenous injection and a promoter dosage effect in terms of transgene expression in vivo.

Systemic delivery of scAAV9/MeCP2hCLN3 reverses motor deficits in $\mathrm{Cln} 3^{\Delta \text { ex7/8 }}$ mice, whereas scAAV9/

$\boldsymbol{\beta}$-actin-hCLN3 is ineffective

Unlike infantile and late-infantile NCL mouse models (CLN1 and CLN2, respectively), $\mathrm{Cln} 3^{\Delta \mathrm{ex} 7 / 8}$ mice do not have a reduced lifespan (Cotman et al., 2002); however, in our hands animals develop robust and persistent motor deficits beginning at 2 months of age, which has also been shown by other groups (Finn et al., 2011; Kovács and Pearce, 2015). To determine whether scAAV9/hCLN3 could reverse motor deficits in $\mathrm{Cln} 3^{\Delta \operatorname{ex} 7 / 8}$ animals, $\mathrm{Cln} 3^{\Delta \mathrm{ex} 7 / 8}$ mice receiving scAAV9/ MeCP2-hCLN3, scAAV9/ $\beta$-actin-hCLN3, or GFP control constructs were subjected to monthly accelerating rotarod testing. As expected, the latency to fall was significantly lower in vehicle-treated $\mathrm{Cln} 3^{\Delta \mathrm{ex} 7 / 8}$ mice compared with WT animals throughout the 5-month study period (Fig. 5). Importantly, motor activity was restored to nearly WT levels only in $\mathrm{Cln} 3^{\Delta \mathrm{ex} 7 / 8}$ mice receiving scAAV9/MeCP2-hCLN3 as early as 1 month after injection, whereas the scAAV9/ $\beta$-actin-hCLN3 and GFP constructs had no significant effect (Fig. 5). Significant improvements in rotarod performance for $\mathrm{Cln} 3^{\Delta \text { ex } 7 / 8}$ mice receiving scAAV9/ MeCP2-hCLN3 continued until 5 months after injection, the latest interval examined. We were not able to extend behavioral assessments beyond 5 months because half of the animals in each group were killed at this interval to assess virus biodistribution and transgene expression and the remaining group size was not sufficient to produce robust results. Collectively, these findings indicate that CLN3 delivery is able to improve motor performance in a JNCL mouse model.

Systemic delivery of scAAV9/MeCP2-hCLN3 suppresses glial activation and reduces lysosomal pathology in the $\mathrm{Cln} 3^{\Delta \mathrm{ex} 7 / 8}$ brain Reactive astrocytes and microglia are known to precede and predict regions of subsequent neuronal loss in JNCL mouse models (Pontikis et al., 2004; Pontikis et al., 2005). In addition, chronic microglial activation can create a toxic environment that induces and/or facilitates neurodegeneration (Vezzani and Viviani, 2015). A potential pathogenic role for microglia in JNCL is supported by our recent study demonstrating that $\mathrm{C} \ln 3^{\Delta \text { ex7/8 }}$ microglia are primed to be proinflammatory (Xiong and Kielian, 2013). To determine the effects of scAAV9/hCLN3 constructs on microglial activation, brain tissues were stained for CD68 5 months after injection. Microglial activation was significantly increased in vehicle treated $C \ln 3^{\Delta \operatorname{ex} 7 / 8}$ mice compared with WT animals in the TH and S1BF (Fig. 6). In both brain regions, only the scAAV9/MeCP2-hCLN3 construct was able to significantly reduce microglial reactivity to near WT levels, whereas the scAAV9/ $\beta$-actin-hCLN3 and GFP constructs had no 


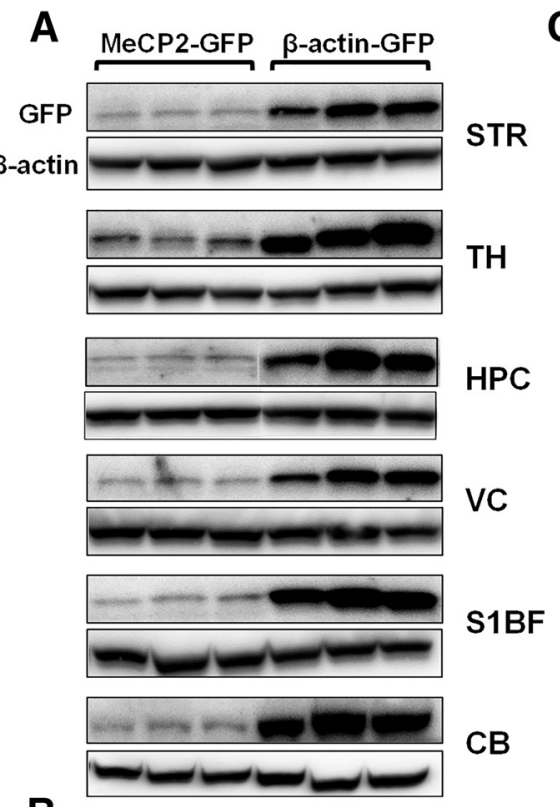

B

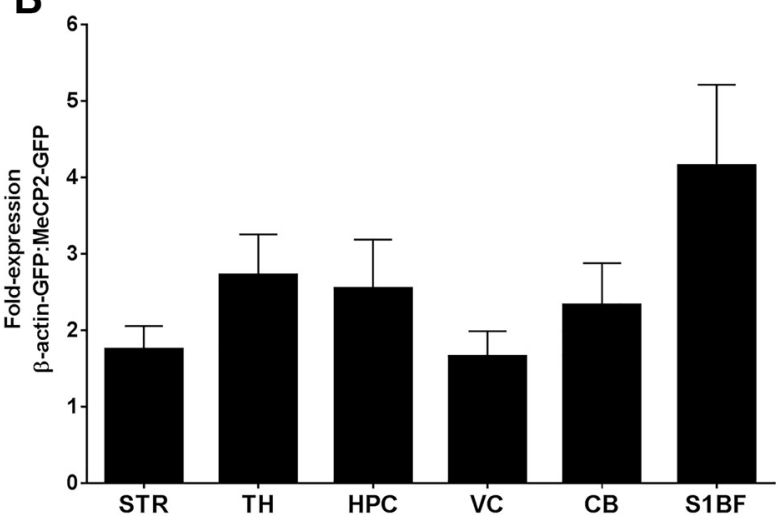

C

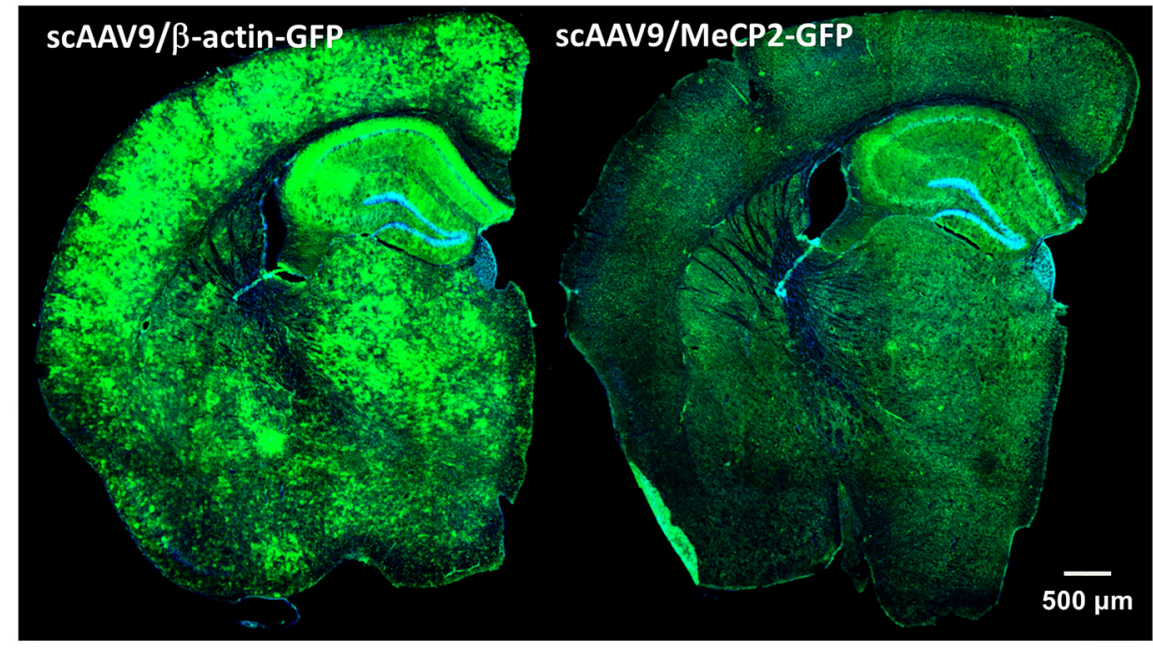

D

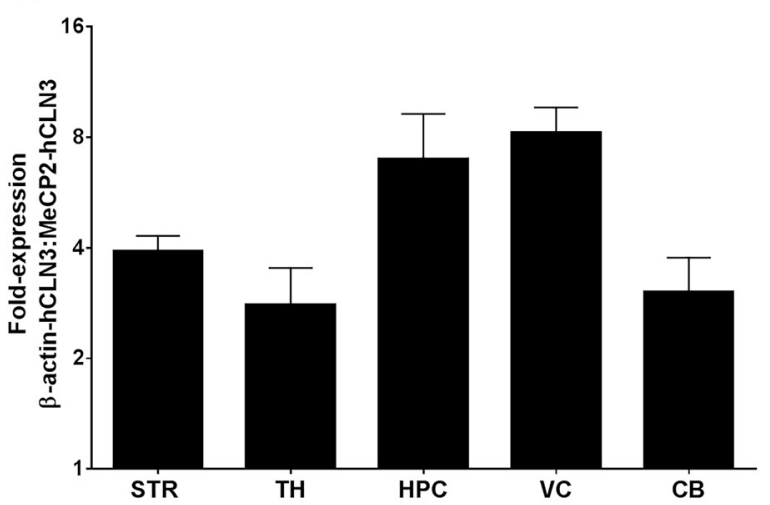

Figure 4. Promoter dosage effect for transgene expression driven by the $\beta$-actin versus MeCP2 promoter. One-month-old $\ln 3^{\Delta \text { ex } 7 / 8}$ mice $(n=4-5 /$ group $)$ received 1 intravenous injection of $2 \times 10^{12} \mathrm{vg}$ of scAAV9/MeCP2-hCLN3, scAAV9/ $\beta$-actin-hCLN3, or GFP constructs, whereupon animals were killed at 5 months after injection for analysis of transgene expression in numerous brain regions. $\boldsymbol{A}, \boldsymbol{B}$, Western blot of GFP expression in the striatum (STR), TH, hippocampus (HPC), VC, S1BF, and cerebellum (CB) with raw $(\boldsymbol{A})$ and quantitative (B) results expressed as the fold change. $\boldsymbol{C}$, Confocal images acquired with the same settings depict differences in GFP expression in the brain of animals injected with scAAV9/ $\beta$-actin-GFP vs scAAV9/MeCP2-GFP. D, hCLN3 expression driven by the MeCP2 versus $\beta$-actin promoters was determined by quantitative PCR after normalization to GAPDH and is presented as the fold change in hCLN3 driven by scAAV9/ $\beta$-actin relative to scAAV9/MeCP2.

significant effect (Fig. 6B). Similar findings were observed with regard to astrocyte activation. Reactive astrocytes were increased in $\mathrm{Cln} 3^{\Delta \mathrm{ex} 7 / 8}$ mice compared with WT animals and only scAAV9/MeCP2-hCLN3 was able to reduce astrocyte activation, although this did not reach statistical significance (Fig. 7). Neither the scAAV9/ $\beta$-actin-hCLN3 nor GFP constructs influenced astrocyte reactivity in $\mathrm{Cln} 3^{\Delta \mathrm{ex} 7 / 8}$ mice (Fig. $7 B$ ). The selectivity of the scAAV9/MeCP2-hCLN3 construct to attenuate glial activation agrees with its ability to improve motor function, suggesting that either low levels of CLN3 expression or preferential transgene expression in neurons afforded by the MeCP2 promoter is critical.

JNCL is characterized by the progressive accumulation of autofluorescent storage material in lysosomes, which is

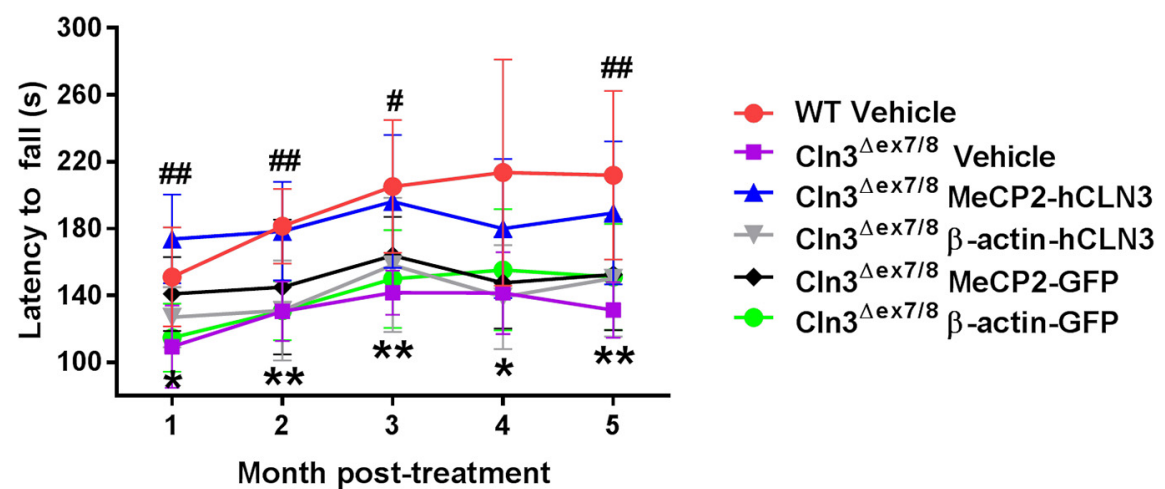

Figure 5. Peripheral delivery of scAAV9/MeCP2-hCLN3 corrects motor deficits in $\mathrm{Cln} 3^{\Delta \mathrm{ex} 7 / 8}$ mice. One-month-old Cln $3^{\Delta e x 7 / 8}$ mice $\left(n=5\right.$-8/group) received 1 intravenous injection of $2 \times 10^{12} \mathrm{vg}$ scAAV9/MeCP2-hCLN3, scAAV9/ $\beta$-actin-hCLN3, or GFP constructs, with vehicle-treated $\ln 3^{\Delta \mathrm{ex} 7 / 8}$ and WT animals as controls, whereupon motor coordination was assessed by monthly repeated accelerating rotarod assay, with results reported as latency to fall. Significant differences between WT and $\ln 3^{\Delta e x 7 / 8}$ vehicle-treated animals are denoted by asterisks; significant changes between $\mathrm{Cln} 3^{\Delta \mathrm{ex} 7 / 8}$ vehicle and $\mathrm{Cln} 3^{\Delta \mathrm{ex} 7 / 8} \mathrm{MeCP2}$-hCLN3 treated mice are denoted by hash signs $\left({ }^{*}\right.$ or $\# p<0.05 ;{ }^{* *}$ or $\# \#<0.01$ using a repeated-measures ANOVA with Tukey's post hoc analysis). 


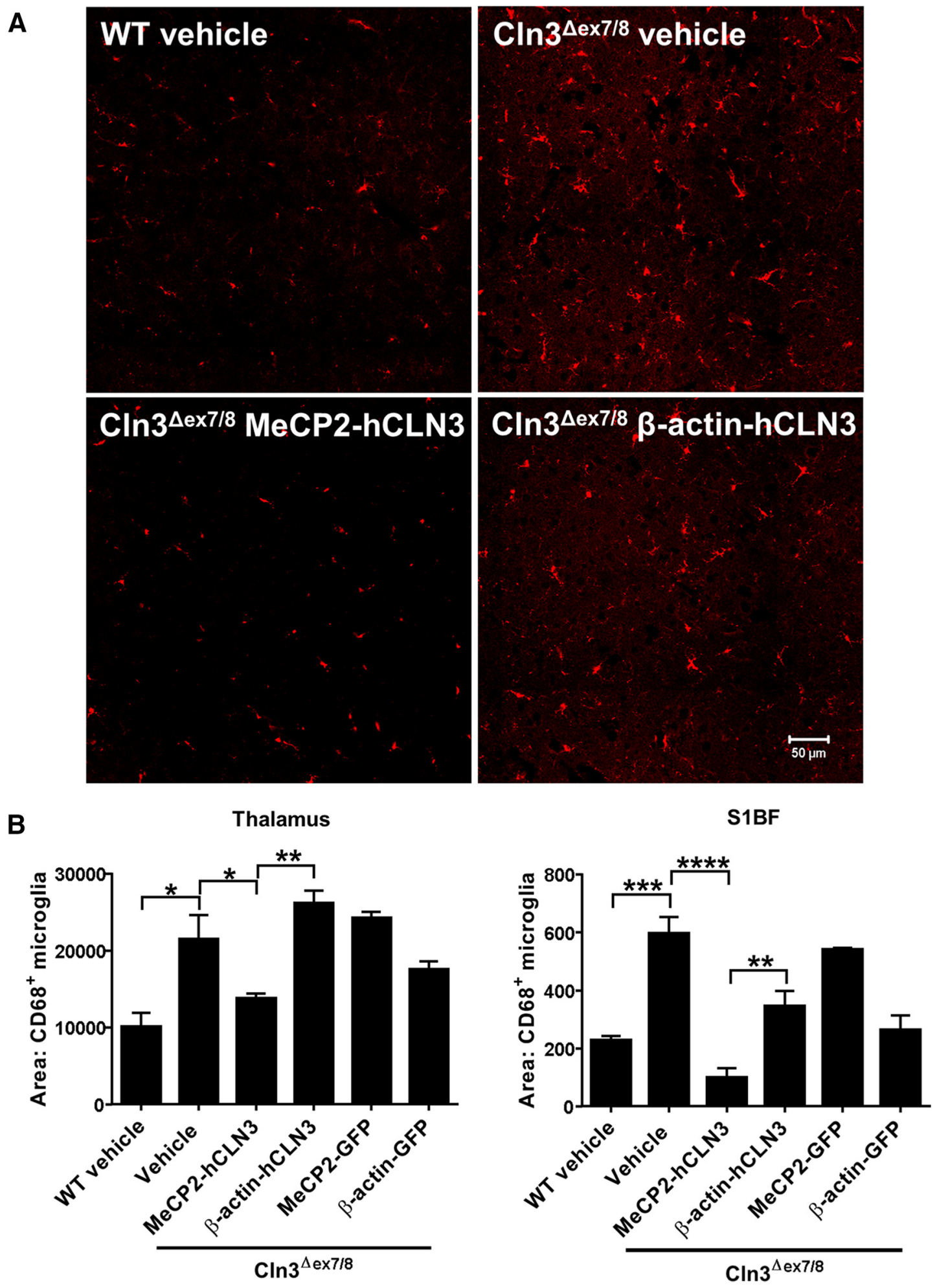

Figure 6. scAAV9/MeCP2-hCLN3 reduces microglial activation in the $\ln 3^{\Delta \text { ex } 7 / 8}$ brain. One-month-old $\ln 3^{\Delta e x 7 / 8}$ mice $(n=4-5 /$ group $)$ received 1 intravenous injection of $2 \times 10^{12} \mathrm{vg} s \mathrm{scAAV} / \mathrm{MeCP2}$ hCLN3, scAAV9/ $\beta$-actin-hCLN3, or GFP constructs, with vehicle-treated $\ln 3^{\Delta e x 7 / 8}$ and WT animals as controls, whereupon microglial activation was evaluated by CD68 immunostaining in the TH and S1BF with representative images of the S1BF shown in $A$ and quantitative analysis in $\boldsymbol{B}$. Significant differences are denoted by asterisks $\left({ }^{*} p<0.05 ;{ }^{* *} p<0.01 ;{ }^{* * *} p<0.001\right.$; ${ }^{* * * *} p<0.0001$ using a mixed linear model).

most pronounced in neurons (Haltia, 2003; Williams et al., 2006). Inclusions are composed of a heterogeneous mixture of mitochondrial ATP synthase subunit c (SCMAS), lipofuscin, and other protein aggregates (Wisniewski et al., 1988; Westlake et al., 1995; Haltia, 2003; Williams et al., 2006; Palmer et al., 2013). Whereas inclusions are not considered to be a direct cause of neuronal death because many inclusion-positive neurons are not lost in the disease, inclusions are commonly used as a biomarker of disease progression (Bronson et al., 1993; International Batten Disease Consortium, 1995; Finn et al., 2011). The extent of LAMP-1 expression is also used as another readout of lysosomal dysfunction (Meikle et al., 1997; Usenovic et al., 2012). There- 
A
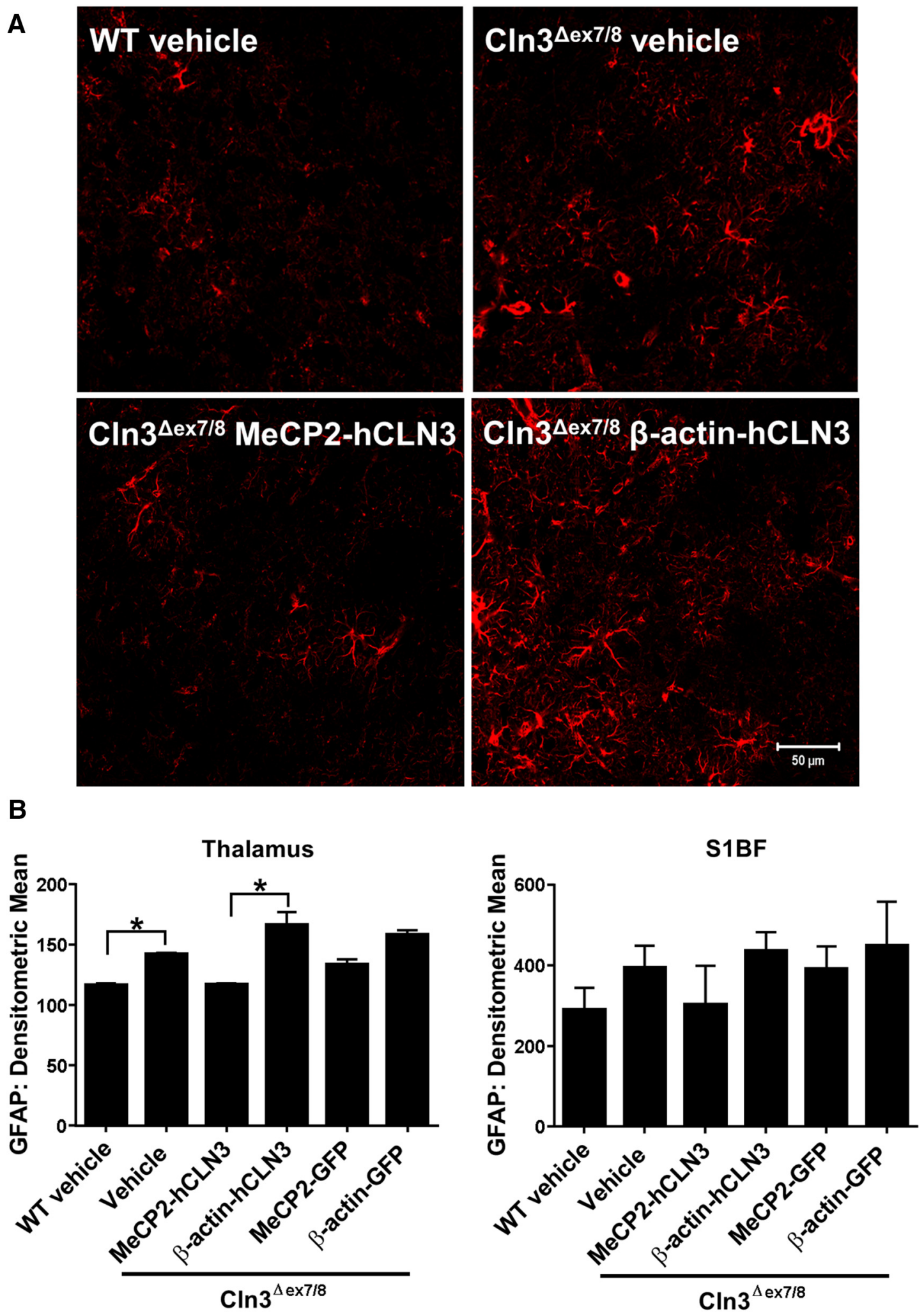

Figure 7. scAAV9/MeCP2-hCLN3 reduces astrocyte activation in the $\left(\ln 3^{\Delta \text { ex7/8 }}\right.$ brain. One-month-old $\ln 3^{\Delta e x 7 / 8}$ mice $\left(n=4-5 /\right.$ group) received 1 intravenous injection of $2 \times 10^{12} \mathrm{vg}$ scAAV9/MeCP2-hCLN3, scAAV9/ $\beta$-actin-hCLN3, or GFP constructs, with vehicle-treated $\ln 3^{\Delta e x 7 / 8}$ and WT animals as controls, whereupon astrocyte activation was evaluated by GFAP immunostaining in the TH and S1BF with representative images of the S1BF shown in $\boldsymbol{A}$ and quantitative analysis in $\boldsymbol{B}$. Significant differences are denoted by asterisks $\left({ }^{*} p<0.05\right.$ using a mixed linear model).

fore, we evaluated the effects of scAAV9/hCLN3 constructs on lysosomal pathology by immunostaining for LAMP-1 and the major storage component SCMAS. As has been shown for other LSDs (Meikle et al., 1997; Saftig et al., 1997; Ryazantsev et al.,
2007), LAMP-1 expression was increased in vehicle-treated $\mathrm{Cln} 3^{\Delta \mathrm{ex} 7 / 8}$ mice compared with WT animals in the TH and S1BF (Fig. 8). Similar to what was observed for glial activation, only the scAAV9/MeCP2-hCLN3 construct was capable of reducing 
A

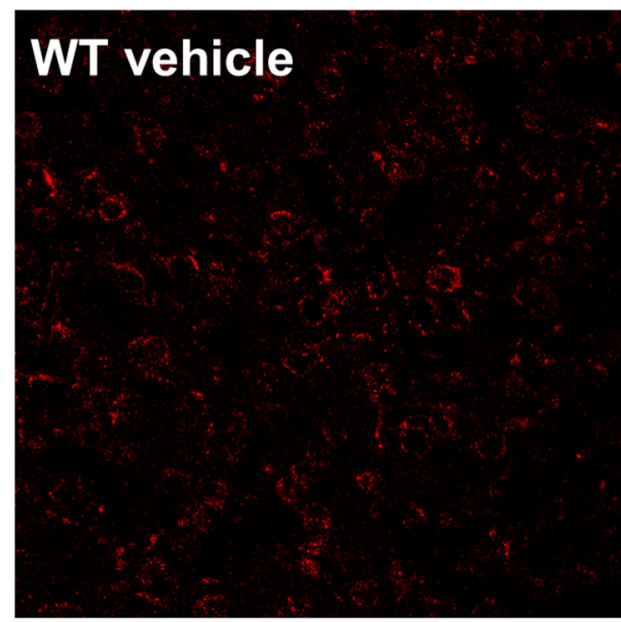

CIn3 $3^{\Delta e x 7 / 8}$ MeCP2-hCLN3

B

Thalamus

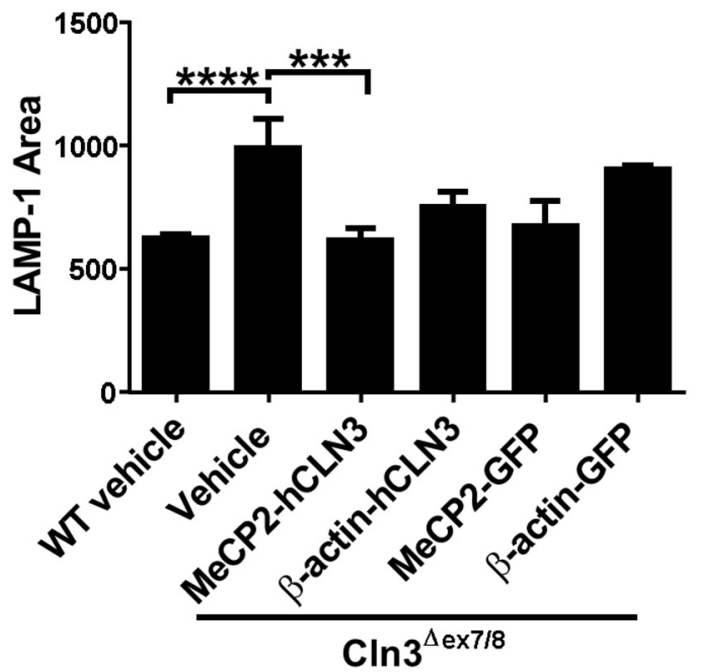

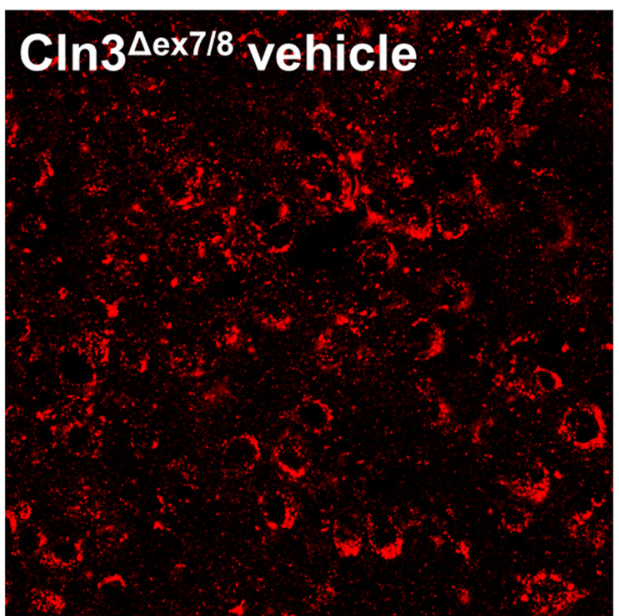

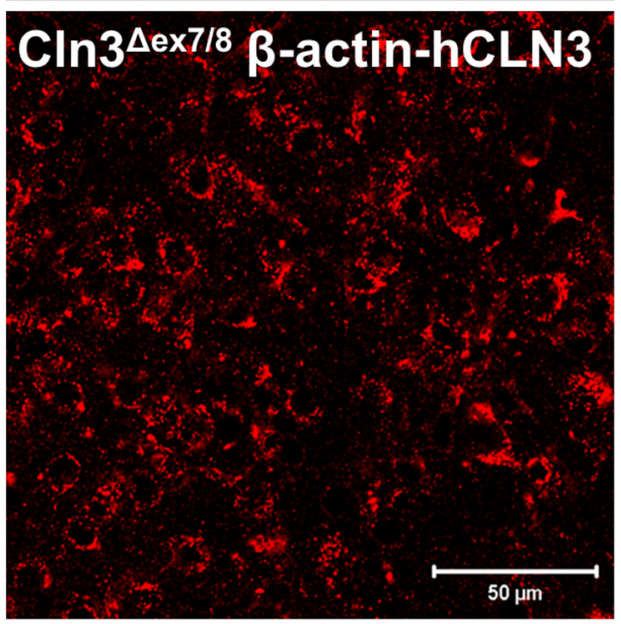

S1BF

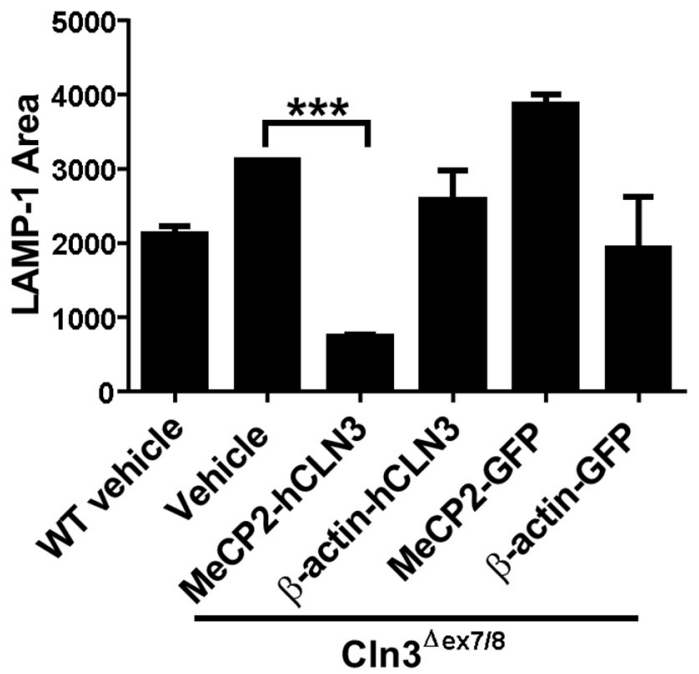

Figure 8. Effect of systemic scAAV9-hCLN3 delivery on lysosomal pathology in the $\mathrm{Cln} 3^{\Delta e x 7 / 8}$ brain. One-month-old $\mathrm{Cln} 3^{\Delta e x 7 / 8}$ mice $(n=4-5 /$ group) received 1 intravenous injection of $2 \times$ $10^{12} \mathrm{vg} \mathrm{scAAV9/MeCP2-hCLN3,} \mathrm{scAAV9/} \beta$-actin-hCLN3, or GFP constructs, with vehicle-treated CIn3 ${ }^{\Delta \text { ex7/8 }}$ and WT animals as controls, whereupon immunofluorescence staining for LAMP-1 was performed in the $\mathrm{TH}$ and $\mathrm{S} 1 \mathrm{BF}$ with representative images of the S1BF shown in $\boldsymbol{A}$ and quantitative analysis in $\boldsymbol{B}$. Significant differences are denoted by asterisks $\left({ }^{* * *} p<0.001\right.$; ${ }^{* * * *} p<0.0001$ using a mixed linear model).

LAMP-1 levels in $C \ln 3^{\Delta \text { ex7/8 }}$ animals, whereas the scAAV9/ $\beta$ actin-hCLN3 or GFP constructs had no effect (Fig. $8 B$ ). As expected, SCMAS was significantly higher in vehicle-treated $\mathrm{Cln} 3^{\Delta \text { ex7/8 }}$ mice compared with WT animals in the TH and S1BF (Fig. 9). $\mathrm{Cln} 3^{\Delta \mathrm{ex} 7 / 8}$ mice injected with scAAV9/MeCP2-hCLN3 displayed a trend toward lower levels of SCMAS in the S1BF, which was not evident with the scAAV9/ $\beta$-actin-hCLN3 or GFP constructs (Fig. 9B). It should be noted that virus injections occurred at 1 month of age, a time when significant lysosomal inclusions are already present (Burkovetskaya et al., 2014), which 
A
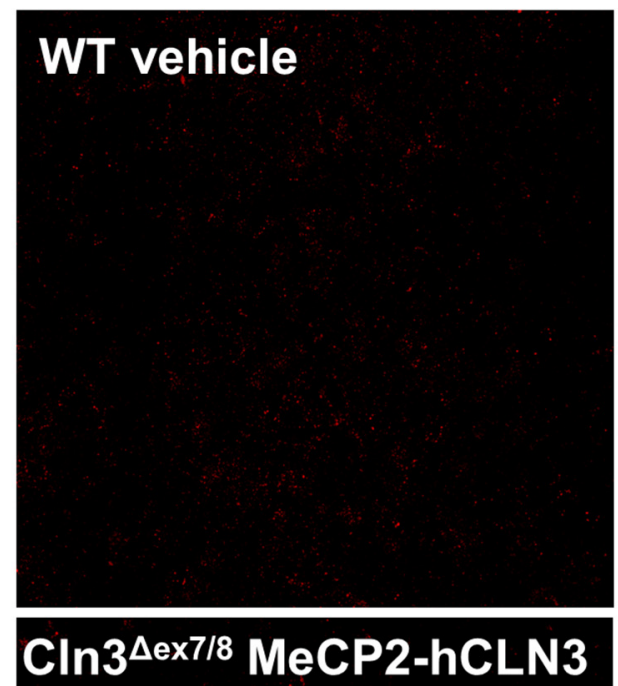

B
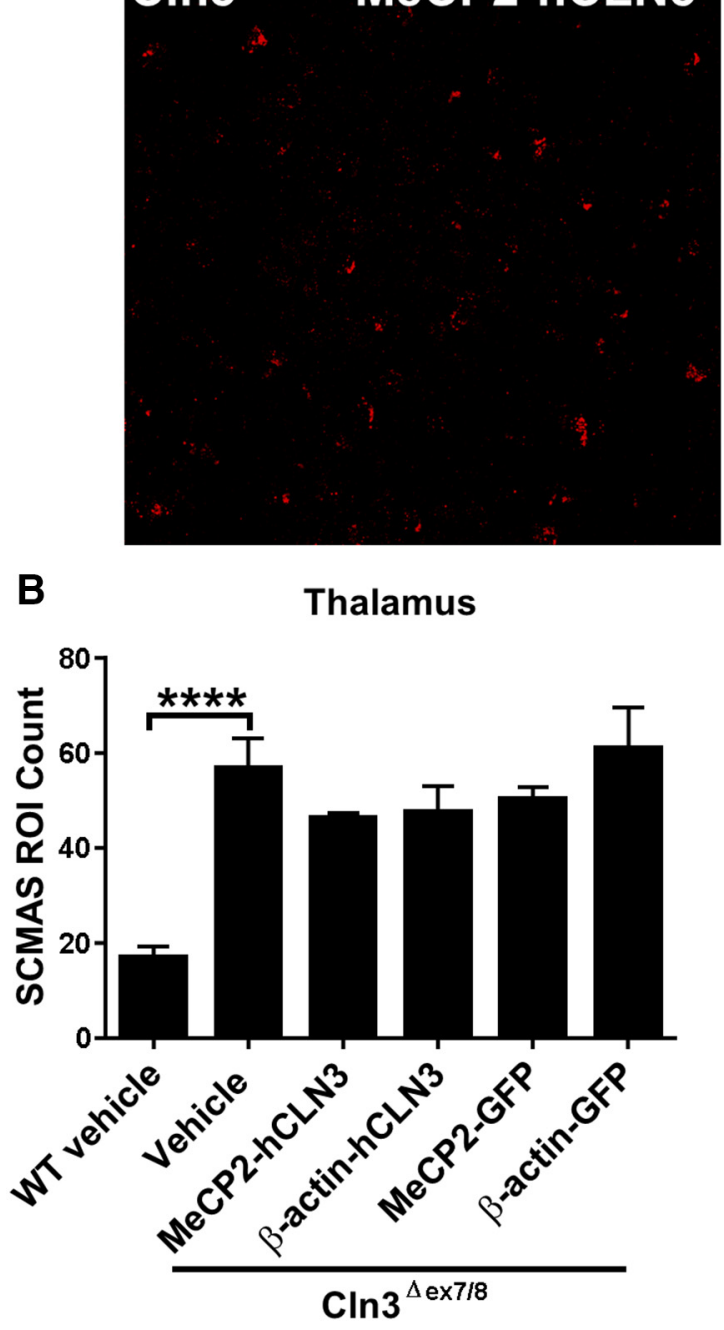

Thalamus
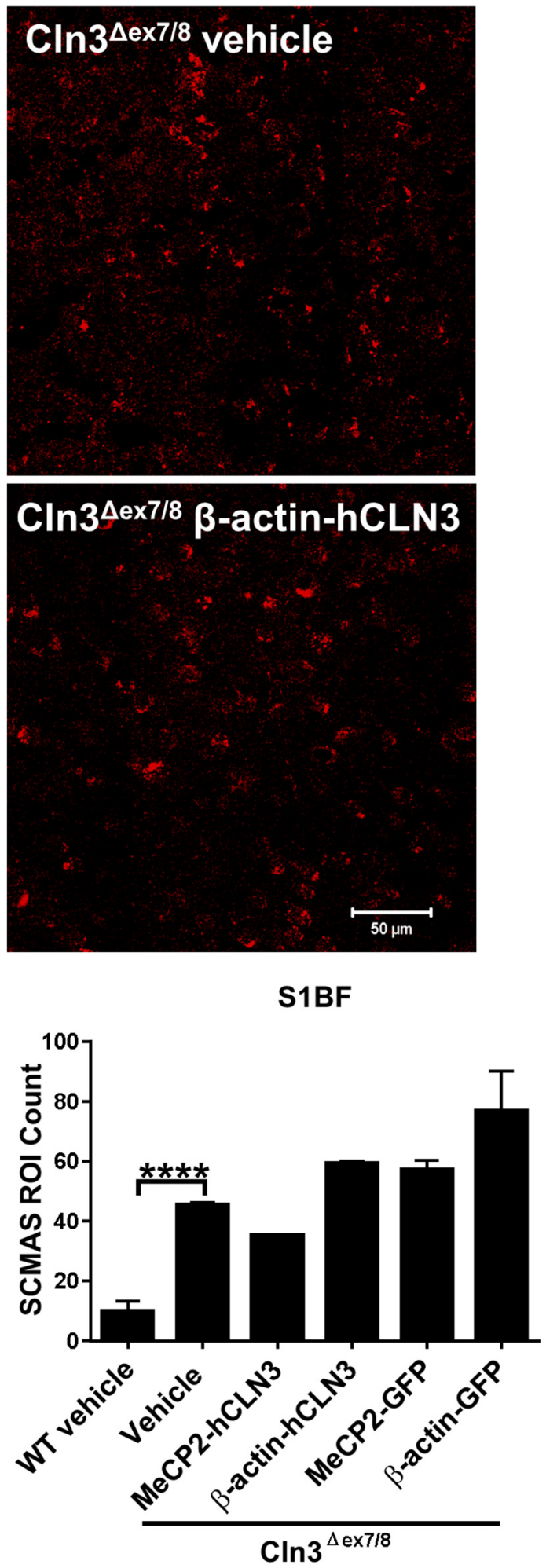

Figure 9. Effect of systemic scAAV9-hCLN3 delivery on lysosomal inclusions in the $\mathrm{Cln} 3^{\Delta \text { ex7 } 7 / 8}$ brain. One-month-old $\mathrm{Cln} 3^{\Delta \text { ex } 7 / 8}$ mice $(n=4-5 /$ group) received 1 intravenous injection of $2 \times$ $10^{12} \mathrm{vg}$ scAAV9/MeCP2-hCLN3, scAAV9/ $\beta$-actin-hCLN3, or GFP constructs, with vehicle-treated $\ln 3^{\Delta e x 7 / 8}$ and WT animals as controls, whereupon immunofluorescence staining for SCMAS was performed in the TH and S1BF with representative images of the S1BF shown in $A$ and quantitative analysis in $B$. Significant differences are denoted by asterisks $(* * * * p<0.0001$ using a mixed linear model).

may make it more difficult to observe dramatic reductions in storage material accumulation.

\section{Discussion}

Currently, no therapeutics exist for JNCL. Although lysosomal inclusions form throughout the body due to the ubiquitous ex- pression of CLN3, the primary site of disease manifestation is the CNS (International Batten Disease Consortium, 1995). Because neurons are the principal cell type lost during the disease, it was critical to devise a strategy to target this population at a relatively high frequency because cross-correction is not possible based on the fact that CLN3 encodes for a transmembrane protein 
(Nugent et al., 2008). To this end, we used scAAV9 harboring the human CLN3 cDNA under the control of either the high- or low-expressing $\beta$-actin and $\mathrm{MeCP} 2$ promoters, respectively, to assess potential gene dosage effects on disease outcome. $\beta$-actin is ubiquitously expressed and its promoter drives high transgene expression (Cheever et al., 2012). In contrast, the MeCP2 promoter is tightly regulated because overexpression by $\sim 2$-fold produces neurological complications (Collins et al., 2004; Luikenhuis et al., 2004). MeCP2 levels rise postnatally and continued expression is essential throughout adult life (McGraw et al., 2011; Cheval et al., 2012; Nguyen et al., 2012), which would ensure that the exogenous $\mathrm{MeCP} 2$ promoter used here to drive hCLN3 is transcriptionally active in juvenile and adult animals. Because the MeCP2 promoter is preferentially active in neurons (Ballas et al., 2009), this also provides an attractive approach to correct intrinsic neuronal defects in JNCL. Indeed, a recent study using the native MeCP2 promoter to drive wild-type MeCP2 expression in a mouse model of Rett syndrome reported widespread neuronal transduction in the hippocampus, cortex, and cerebellum after systemic intravenous injection of adult animals, which rescued behavioral and cellular deficits (Garg et al., 2013). In our study, we selected MeCP2 instead of the CLN3 promoter to drive low transgene expression because the regulatory elements of CLN3 are not well defined.

This study is the first to use systemic scAAV9 delivery to drive CLN3 expression in the CNS and, importantly, only a single intravenous injection of scAAV9/MeCP2-hCLN3 was required to improve motor function, glial activation, and lysosomal pathology. In addition, intravenous injection led to widespread transgene expression in the brain, spinal cord, and eye. scAAV9 did not affect liver function negatively, as determined by blood chemistry analysis, and all mice receiving scAAV9 constructs demonstrated equivalent weight gain. None of the scAAV9 constructs elicited signs of peripheral inflammation and there was no gross evidence of tumor formation in the liver at either 5 or 13 months after injection (data not shown). Hepatocellular carcinoma has been reported in some mouse studies with specific AAV serotypes (Donsante et al., 2001; Rosas et al., 2012; Chandler et al., 2016); however, this is typically observed when virus is administered to neonatal mice (Donsante et al., 2007; Chandler et al., 2015), which differs from our study, in which scAAV9 was used in juvenile animals. Collectively, these findings demonstrate the safety and tolerability of scAAV9/hCLN3, which are important attributes when considering the potential translation of this gene delivery approach.

scAAV9 has been well characterized within the CNS after systemic intravenous injection (Foust et al., 2009; Foust et al., 2013; Kantor et al., 2014; Murrey et al., 2014; Duncan et al., 2015). Specifically, the AAV9 capsid allows the virus to cross the bloodbrain barrier, resulting in stable CNS transgene expression. Prior reports have demonstrated that the age at which animals are injected can influence virus biodistribution and cell type targeting. For example, intravenous injection of P1 mice with a scAAV9/ $\beta$ actin-GFP construct led to a large population of transgene ${ }^{+}$neurons and astrocytes (Foust et al., 2009). In contrast, intravenous injections of mice that were $\mathrm{P} 30$ or older with scAAV $9 / \beta$-actinGFP primarily resulted in astrocyte targeting with few transgene ${ }^{+}$ neurons. In addition to mouse age, the promoter used to drive transgene expression can also have a major impact. For example, intravenous injection of a scAAV9/MeCP2-MeCP2 construct in a mouse model of Rett syndrome led to robust transgene expression in neurons despite the fact that animals did not receive the virus until adulthood (i.e., 2-3 months of age) (Garg et al., 2013). Therefore, other mechanisms are at play in addition to age at injection, indicating that cell-type promoter preference may also influence transgene levels. In our studies, the scAAV9/MeCP2GFP construct led to significantly more transgene ${ }^{+}$neurons than scAAV9/ $\beta$-actin-GFP, suggesting a promoter preference for MeCP2 in neurons. This is also supported by studies showing that the $\mathrm{MeCP} 2$ promoter is expressed preferentially in neurons compared with glia (Collins et al., 2004; Luikenhuis et al., 2004). Because both the MeCP2 and $\beta$-actin constructs used the same viral capsid (AAV9), these differences likely result from promoter preferences in each cell population.

In terms of disease outcomes, only the scAAV9/MeCP2hCLN3 construct was capable of improving motor function, attenuating glial activation, and reducing lysosomal pathology, all hallmarks of JNCL (Pontikis et al., 2004; Finn et al., 2011). However, it remains to be determined whether the beneficial effects of scAAV9/MeCP2-hCLN3 resulted from lower transgene levels or preferential expression in neurons. Because we did not observe any adverse effects with scAAV9/ $\beta$-actin-hCLN3 that drives a 3 to 8 -fold increase in hCLN3 depending on the brain region, this suggests that the beneficial effects of scAAV9/MeCP2-hCLN3 are likely due to preferential transgene expression in neurons. However, additional studies are needed to address this possibility definitively, including the generation of neuronal- and astrocytetargeted hCLN3 constructs (i.e., synapsin-hCLN3 and GFAPhCLN3, respectively). We are currently pursuing the longevity of scAAV9/MeCP2-hCLN3 gene transfer effects with larger cohorts of animals in conjunction with cell-type-selective targeting to neurons or astrocytes, such that coincident data can be collected with accelerating rotarod and histopathology (the former of which requires large group sizes of $\geq 8$ ). Preliminary analysis was performed with the limited numbers of $\mathrm{Cln} 3^{\Delta \text { ex } 7 / 8}$ mice that were killed at 13 months after injection in the current study, including unbiased stereology to estimate neurons in the VPM/VPL thalamic nuclei. Although a prior study reported thalamic neuron loss in $\mathrm{Cln} 3^{\Delta \mathrm{ex} 7 / 8}$ mice on a mixed 129Sv/Ev/CD1 background at 12 months (Pontikis et al., 2005), this reduction was modest and we did not observe any differences in neuronal counts in the current study between vehicle-treated WT and $\mathrm{Cln} 3^{\Delta \mathrm{ex} 7 / 8}$ animals on a C57BL/6 background, which is known to harbor milder disease phenotypes. The fact that we could not demonstrate evidence of neuronal loss in $\mathrm{Cln} 3^{\Delta \mathrm{ex} 7 / 8}$ mice precluded our ability to assess the effects of CLN3 gene delivery on promoting neuronal survival. Nevertheless, we found that neuron counts in the thalamus were similar between WT animals and $C \ln 3^{\Delta \operatorname{ex} 7 / 8}$ mice receiving either the MeCP2 or $\beta$-actin hCLN3 constructs at 13 months after injection (data not shown). This indicates that CLN3 gene delivery did not exert any deleterious effects on neurons, which is an important indicator of safety. Likewise, although our results demonstrated that elevated hCLN3 expression driven by the $\beta$-actin promoter did not improve disease outcome, there was no evidence of toxicity because scAAV $9 / \beta$-actinhCLN3 did not worsen motor performance, glial activation, lysosomal pathology, or blood chemistry values in $C \ln 3^{\Delta \operatorname{ex} 7 / 8}$ mice. Collectively, these results indicate that, unlike prior in vitro studies, elevated hCLN3 expression in vivo is not deleterious, as determined by the readouts examined here. This is also supported by a study with rhAAV.10/ $\beta$-actin-CLN3 in which direct intracranial injection was not associated with adverse effects even though hCLN3 mRNA expression was elevated 12- to 100 -fold (Sondhi et al., 2014).

A major hallmark of JNCL is lysosomal storage material accumulation . Although this heterogeneous material, primarily composed of SCMAS, has not been implicated directly in neuronal 
death (Palmer et al., 2013), inclusion quantification is still widely used to assess lysosomal function and disease progression. Only scAAV9/MeCP2-hCLN3 led to reductions in SCMAS accumulation in $\mathrm{Cln} 3^{\Delta \mathrm{ex} 7 / 8}$ mice, although this did not reach statistical significance. Another marker of lysosomal dysfunction is increased LAMP-1 expression and, similar to SCMAS, only scAAV9/MeCP2-hCLN3 was capable of significantly reducing LAMP-1 in the $C \ln 3^{\Delta \operatorname{ex} 7 / 8}$ brain to WT levels. This finding was substantial given the fact that virus administration was delayed until 1 month of age, when significant lysosomal pathology had already manifested (Burkovetskaya et al., 2014).

Like many other LSDs, JNCL mouse models are typified by early glial activation (i.e., 1-3 months of age) that coincides with regions of modest neuronal loss that occurs much later in disease (i.e., 12-18 months; Pontikis et al., 2005; Burkovetskaya et al., 2014). Although initial glial activation may represent a neuroprotective attempt, this clearly is not achieved and chronic inflammation can create a neurotoxic environment (Fernandes-Alnemri et al., 2009). Indeed, our prior work revealed that $\mathrm{Cln} 3^{\Delta \mathrm{ex} 7 / 8}$ microglia are primed to release exaggerated levels of numerous proinflammatory cytokines/ chemokines (Xiong and Kielian, 2013). Here, we report that only the scAAV9/MeCP2-hCLN3 construct was able to reduce glial activation, which coincided with improvements in motor function. By extension, this suggests that either: (1) reactive microglia and/or astrocytes contribute to CNS dysfunction in early disease or (2) preferential transgene expression in neurons driven by the MeCP2 promoter improves neuronal homeostasis, such that surrounding glia do not sense neuronal danger signals and thus are less activated. These possibilities currently remain speculative and require additional studies using cell-type-specific scAAV9 constructs. There is a longstanding question of what occurs first, inflammation induced by reactive glia or neurons releasing danger signals to induce glial activation and inflammation (Bosch and Kielian, 2015). In other LSDs, such as Gaucher disease, inflammation is elicited by either neurons or astrocytes, but not from microglia (Enquist et al., 2007; Vitner et al., 2012). In our studies, the scAAV9/ $\beta$-actin-hCLN3 construct predominantly drove transgene expression in astrocytes; however, it had no effect on glial activation. Furthermore, relatively fewer transgenepositive astrocytes and no microglia were observed after scAAV9/MeCP2-hCLN3 injection. This implies that glia sense signals from diseased neurons because most were still CLN3 deficient yet their activation status was reduced significantly. This suggests that neurons are a primary driver of disease progression, although a confounding role from activated glia cannot be disregarded at this time. The importance of cellintrinsic CLN3 loss in neurons is also supported by the finding that, although the percentages of transgene-positive cells were approximately similar with both viruses (Fig. $2 A$ ), the MeCP2 construct resulted in significantly more transgene-positive neurons compared with $\beta$-actin and was associated with therapeutic efficacy. This is likely attributed to preferential promoter activity in neurons because both promoter constructs were delivered by the same viral capsid (AAV9).

In summary, a highly regulated, neuron-targeted promoter (MeCP2) used to drive hCLN3 expression restored motor function and decreased glial activation and lysosomal pathology in the $\mathrm{Cln} 3^{\Delta \text { ex7/8}}$ brain. Our study is the first to show that systemic gene delivery with scAAV9 can be used to improve a lysosomal transmembrane mutation. This represents a critical first step toward a viable therapeutic for JNCL.

\section{References}

Aberg L, Liewendahl K, Nikkinen P, Autti T, Rinne JO, Santavuori P (2000) Decreased striatal dopamine transporter density in JNCL patients with parkinsonian symptoms. Neurology 54:1069-1074. CrossRef Medline

Acland GM, Aguirre GD, Bennett J, Aleman TS, Cideciyan AV, Bennicelli J, Dejneka NS, Pearce-Kelling SE, Maguire AM, Palczewski K, Hauswirth WW, Jacobson SG (2005) Long-term restoration of rod and cone vision by single dose rAAV-mediated gene transfer to the retina in a canine model of childhood blindness. Mol Ther 12:1072-1082. CrossRef Medline

Adachi M, Keefer EW, Jones FS (2005) A segment of the Mecp2 promoter is sufficient to drive expression in neurons. Hum Mol Genet 14:3709-3722. CrossRef Medline

Aschauer DF, Kreuz S, Rumpel S (2013) Analysis of transduction efficiency, tropism and axonal transport of AAV serotypes 1, 2, 5, 6, 8 and 9 in the mouse brain. PLoS One 8:e76310. CrossRef Medline

Autti T, Raininko R, Vanhanen SL, Santavuori P (1996) MRI of neuronal ceroid lipofuscinosis. I. Cranial MRI of 30 patients with juvenile neuronal ceroid lipofuscinosis. Neuroradiology 38:476-482. CrossRef Medline

Ballas N, Lioy DT, Grunseich C, Mandel G (2009) Non-cell autonomous influence of MeCP2-deficient glia on neuronal dendritic morphology. Nat Neurosci 12:311-317. CrossRef Medline

Banovic D, Khorramshahi O, Owald D, Wichmann C, Riedt T, Fouquet W, Tian R, Sigrist SJ, Aberle H (2010) Drosophila neuroligin 1 promotes growth and postsynaptic differentiation at glutamatergic neuromuscular junctions. Neuron 66:724-738. CrossRef Medline

Bemelmans AP, Duqué S, Riviere C, Astord S, Desrosiers M, Marais T, Sahel JA, Voit T, Barkats M (2013) A single intravenous AAV9 injection mediates bilateral gene transfer to the adult mouse retina. PLoS One 8:e61618. CrossRef Medline

Bosch ME, Kielian T (2015) Neuroinflammatory paradigms in lysosomal storage diseases. Front Neurosci 9:417. CrossRef Medline

Bronson RT, Lake BD, Cook S, Taylor S, Davisson MT (1993) Motor neuron degeneration of mice is a model of neuronal ceroid lipofuscinosis (Batten's disease). Ann Neurol 33:381-385. CrossRef Medline

Burkovetskaya M, Karpuk N, Xiong J, Bosch M, Boska MD, Takeuchi H, Suzumura A, Kielian T (2014) Evidence for aberrant astrocyte hemichannel activity in juvenile neuronal ceroid lipofuscinosis (JNCL). PLoS One 9:e95023. CrossRef Medline

Chandler RJ, LaFave MC, Varshney GK, Trivedi NS, Carrillo-Carrasco N, Senac JS, Wu W, Hoffmann V, Elkahloun AG, Burgess SM, Venditti CP (2015) Vector design influences hepatic genotoxicity after adenoassociated virus gene therapy. J Clin Invest 125:870-880. CrossRef Medline

Chandler RJ, LaFave MC, Varshney GK, Burgess SM, Venditti CP (2016) Genotoxicity in mice following AAV gene delivery: a safety concern for human gene therapy? Mol Ther 24:198-201. CrossRef Medline

Cheever TR, Li B, Ervasti JM (2012) Restricted morphological and behavioral abnormalities following ablation of beta-actin in the brain. PLoS One 7:e32970. CrossRef Medline

Cheval H, Guy J, Merusi C, De Sousa D, Selfridge J, Bird A (2012) Postnatal inactivation reveals enhanced requirement for $\mathrm{MeCP} 2$ at distinct age windows. Hum Mol Genet 21:3806-3814. CrossRef Medline

Collins AL, Levenson JM, Vilaythong AP, Richman R, Armstrong DL, Noebels JL, David Sweatt J, Zoghbi HY (2004) Mild overexpression of $\mathrm{MeCP} 2$ causes a progressive neurological disorder in mice. Hum Mol Genet 13:2679-2689. CrossRef Medline

Cooper JD, Tarczyluk MA, Nelvagal HR (2015) Towards a new understanding of NCL pathogenesis. Biochim Biophys Acta 1852:2256-2261. CrossRef Medline

Costes SV, Daelemans D, Cho EH, Dobbin Z, Pavlakis G, Lockett S (2004) Automatic and quantitative measurement of protein-protein colocalization in live cells. Biophys J 86:3993-4003. CrossRef Medline

Cotman SL, Staropoli JF (2012) The juvenile Batten disease protein, CLN3, and its role in regulating anterograde and retrograde post-Golgi trafficking. Clin Lipidol 7:79-91. CrossRef Medline

Cotman SL, Vrbanac V, Lebel LA, Lee RL, Johnson KA, Donahue LR, Teed AM, Antonellis K, Bronson RT, Lerner TJ, MacDonald ME (2002) Cln3(Deltaex7/8) knock-in mice with the common JNCL mutation exhibit progressive neurologic disease that begins before birth. Hum Mol Genet 11:2709-2721. CrossRef Medline 
Daya S, Berns KI (2008) Gene therapy using adeno-associated virus vectors. Clin Microbiol Rev 21:583-593. CrossRef Medline

Donsante A, Vogler C, Muzyczka N, Crawford JM, Barker J, Flotte T, Campbell-Thompson M, Daly T, Sands MS (2001) Observed incidence of tumorigenesis in long-term rodent studies of rAAV vectors. Gene Ther 8:1343-1346. CrossRef Medline

Donsante A, Miller DG, Li Y, Vogler C, Brunt EM, Russell DW, Sands MS (2007) AAV vector integration sites in mouse hepatocellular carcinoma. Science 317:477. CrossRef Medline

Duncan FJ, Naughton BJ, Zaraspe K, Murrey DA, Meadows AS, Clark KR, Newsom DE, White P, Fu H, McCarty DM (2015) Broad functional correction of molecular impairments by systemic delivery of scAAVrh74hSGSH gene delivery in MPS IIIA mice. Mol Ther 23:638-647. CrossRef Medline

Duqué S, Joussemet B, Riviere C, Marais T, Dubreil L, Douar AM, Fyfe J, Moullier P, Colle MA, Barkats M (2009) Intravenous administration of self-complementary AAV9 enables transgene delivery to adult motor neurons. Mol Ther 17:1187-1196. CrossRef Medline

Eliason SL, Stein CS, Mao Q, Tecedor L, Ding SL, Gaines DM, Davidson BL (2007) A knock-in reporter model of Batten disease. J Neurosci 27: 9826-9834. CrossRef Medline

Enquist IB, Lo Bianco C, Ooka A, Nilsson E, Månsson JE, Ehinger M, Richter J, Brady RO, Kirik D, Karlsson S (2007) Murine models of acute neuronopathic Gaucher disease. Proc Natl Acad Sci U S A 104:17483-17488. CrossRef Medline

Fernandes-Alnemri T, Yu JW, Datta P, Wu J, Alnemri ES (2009) AIM2 activates the inflammasome and cell death in response to cytoplasmic DNA. Nature 458:509-513. CrossRef Medline

Finn R, Kovács AD, Pearce DA (2011) Altered sensitivity of cerebellar granule cells to glutamate receptor overactivation in the $\operatorname{Cn} 3$ (Deltaex7/8)knock-in mouse model of juvenile neuronal ceroid lipofuscinosis. Neurochem Int 58:648-655. CrossRef Medline

Foust KD, Nurre E, Montgomery CL, Hernandez A, Chan CM, Kaspar BK (2009) Intravascular AAV9 preferentially targets neonatal neurons and adult astrocytes. Nat Biotechnol 27:59-65. CrossRef Medline

Foust KD, Wang X, McGovern VL, Braun L, Bevan AK, Haidet AM, Le TT, Morales PR, Rich MM, Burghes AH, Kaspar BK (2010) Rescue of the spinal muscular atrophy phenotype in a mouse model by early postnatal delivery of SMN. Nat Biotechnol 28:271-274. CrossRef Medline

Foust KD, Salazar DL, Likhite S, Ferraiuolo L, Ditsworth D, Ilieva H, Meyer K, Schmelzer L, Braun L, Cleveland DW, Kaspar BK (2013) Therapeutic AAV9-mediated suppression of mutant SOD1 slows disease progression and extends survival in models of inherited ALS. Mol Ther 21:2148-2159. CrossRef Medline

Gadalla KK, Bailey ME, Spike RC, Ross PD, Woodard KT, Kalburgi SN, Bachaboina L, Deng JV, West AE, Samulski RJ, Gray SJ, Cobb SR (2013) Improved survival and reduced phenotypic severity following AAV9/ MECP2 gene transfer to neonatal and juvenile male Mecp2 knockout mice. Mol Ther 21:18-30. CrossRef Medline

Garg SK, Lioy DT, Cheval H, McGann JC, Bissonnette JM, Murtha MJ, Foust KD, Kaspar BK, Bird A, Mandel G (2013) Systemic delivery of MeCP2 rescues behavioral and cellular deficits in female mouse models of Rett syndrome. J Neurosci 33:13612-13620. CrossRef Medline

Geifman N, Rubin E (2013) The mouse age phenome knowledgebase and disease-specific inter-species age mapping. PLoS One 8:e81114. CrossRef Medline

Getty AL, Pearce DA (2011) Interactions of the proteins of neuronal ceroid lipofuscinosis: clues to function. Cell Mol Life Sci 68:453-474. CrossRef Medline

Haltia M (2003) The neuronal ceroid-lipofuscinoses. J Neuropathol Exp Neurol 62:1-13. CrossRef Medline

International Batten Disease Consortium (1995) Isolation of a novel gene underlying Batten disease, CLN3. Cell 82:949-957. Medline

Kantor B, Bailey RM, Wimberly K, Kalburgi SN, Gray SJ (2014) Methods for gene transfer to the central nervous system. Adv Genet 87:125-197. CrossRef Medline

Kovács AD, Pearce DA (2015) Finding the most appropriate mouse model of juvenile CLN3 (Batten) disease for therapeutic studies: the importance of genetic background and gender. Dis Model Mech 8:351-361. CrossRef Medline

Kyttälä A, Lahtinen U, Braulke T, Hofmann SL (2006) Functional biology of the neuronal ceroid lipofuscinoses (NCL) proteins. Biochim Biophys Acta 1762:920-933. CrossRef Medline

Lee JH, Sowada MJ, Boudreau RL, Aerts AM, Thedens DR, Nopoulos P, Davidson BL (2014) Rhes suppression enhances disease phenotypes in Huntington's disease mice. J Huntingtons Dis 3:65-71. CrossRef Medline

Luikenhuis S, Giacometti E, Beard CF, Jaenisch R (2004) Expression of $\mathrm{MeCP} 2$ in postmitotic neurons rescues Rett syndrome in mice. Proc Natl Acad Sci U S A 101:6033-6038. CrossRef Medline

Macauley SL, Roberts MS, Wong AM, McSloy F, Reddy AS, Cooper JD, Sands MS (2012) Synergistic effects of central nervous system-directed Gene Ther and bone marrow transplantation in the murine model of infantile neuronal ceroid lipofuscinosis. Ann Neurol 71:797-804. CrossRef Medline

McCarty DM, Monahan PE, Samulski RJ (2001) Self-complementary recombinant adeno-associated virus (scAAV) vectors promote efficient transduction independently of DNA synthesis. Gene Ther 8:1248-1254. CrossRef Medline

McGraw CM, Samaco RC, Zoghbi HY (2011) Adult neural function requires MeCP2. Science 333:186. CrossRef Medline

Meikle PJ, Brooks DA, Ravenscroft EM, Yan M, Williams RE, Jaunzems AE, Chataway TK, Karageorgos LE, Davey RC, Boulter CD, Carlsson SR, Hopwood JJ (1997) Diagnosis of lysosomal storage disorders: evaluation of lysosome-associated membrane protein LAMP-1 as a diagnostic marker. Clin Chem 43:1325-1335. Medline

Meyer K, Ferraiuolo L, Schmelzer L, Braun L, McGovern V, Likhite S, Michels O, Govoni A, Fitzgerald J, Morales P, Foust KD, Mendell JR, Burghes AH, Kaspar BK (2015) Improving single injection CSF delivery of AAV9mediated Gene Ther for SMA: a dose-response study in mice and nonhuman primates. Mol Ther 23:477-487. CrossRef Medline

Murrey DA, Naughton BJ, Duncan FJ, Meadows AS, Ware TA, Campbell K, Bremer WG, Walker C, Goodchild L, Bolon B, La Perle K, Flanigan K, McBride KL, McCarty DM, Fu H (2014) Feasibility and safety of systemic rAAV9-hNAGLU delivery for treating MPS IIIB: toxicology, biodistribution and immunological assessments in primates. Hum Gene Ther Clin Dev. In press.

Nguyen MV, Du F, Felice CA, Shan X, Nigam A, Mandel G, Robinson JK, Ballas N (2012) MeCP2 is critical for maintaining mature neuronal networks and global brain anatomy during late stages of postnatal brain development and in the mature adult brain. J Neurosci 32:10021-10034. CrossRef Medline

Nugent T, Mole SE, Jones DT (2008) The transmembrane topology of Batten disease protein CLN3 determined by consensus computational prediction constrained by experimental data. FEBS Lett 582:1019-1024. CrossRef Medline

Palmer DN, Barry LA, Tyynelä J, Cooper JD (2013) NCL disease mechanisms. Biochim Biophys Acta 1832:1882-1893. CrossRef Medline

Passini MA, Dodge JC, Bu J, Yang W, Zhao Q, Sondhi D, Hackett NR, Kaminsky SM, Mao Q, Shihabuddin LS, Cheng SH, Sleat DE, Stewart GR, Davidson BL, Lobel P, Crystal RG (2006) Intracranial delivery of CLN2 reduces brain pathology in a mouse model of classical late infantile neuronal ceroid lipofuscinosis. J Neurosci 26:1334-1342. CrossRef Medline

Pearce DA, Sherman F (1998) A yeast model for the study of Batten disease. Proc Natl Acad Sci U S A 95:6915-6918. CrossRef Medline

Pontikis CC, Cella CV, Parihar N, Lim MJ, Chakrabarti S, Mitchison HM, Mobley WC, Rezaie P, Pearce DA, Cooper JD (2004) Late onset neurodegeneration in the Cln3-/- mouse model of juvenile neuronal ceroid lipofuscinosis is preceded by low level glial activation. Brain Res 1023: 231-242. CrossRef Medline

Pontikis CC, Cotman SL, MacDonald ME, Cooper JD (2005) Thalamocortical neuron loss and localized astrocytosis in the Cln3Deltaex7/8 knock-in mouse model of Batten disease. Neurobiol Dis 20:823-836. CrossRef Medline

Rakheja D, Narayan SB, Bennett MJ (2007) Juvenile neuronal ceroidlipofuscinosis (Batten disease): a brief review and update. Curr Mol Med 7:603-608. CrossRef Medline

Rosas LE, Grieves JL, Zaraspe K, La Perle KM, Fu H, McCarty DM (2012) Patterns of scAAV vector insertion associated with oncogenic events in a mouse model for genotoxicity. Mol Ther 20:2098-2110. CrossRef Medline

Ryazantsev S, Yu WH, Zhao HZ, Neufeld EF, Ohmi K (2007) Lysosomal accumulation of SCMAS (subunit $\mathrm{c}$ of mitochondrial ATP synthase) in neurons of the mouse model of mucopolysaccharidosis III B. Mol Genet Metab 90:393-401. CrossRef Medline

Saftig P, Hartmann D, Lullmann-Rauch R, Wolff J, Evers M, Köster A, Het- 
man M, von Figura K, Peters C (1997) Mice deficient in lysosomal acid phosphatase develop lysosomal storage in the kidney and central nervous system. J Biol Chem 272:18628-18635. CrossRef Medline

Schultz ML, Tecedor L, Chang M, Davidson BL (2011) Clarifying lysosomal storage diseases. Trends Neurosci 34:401-410. CrossRef Medline

Sondhi D, Scott EC, Chen A, Hackett NR, Wong AM, Kubiak A, Nelvagal HR, Pearse Y, Cotman SL, Cooper JD, Crystal RG (2014) Partial correction of the CNS lysosomal storage defect in a mouse model of juvenile neuronal ceroid lipofuscinosis by neonatal CNS administration of an adenoassociated virus serotype rh.10 vector expressing the human CLN3 gene. Hum Gene Ther 25:223-239. CrossRef Medline

Tokola AM, Salli EK, Åberg LE, Autti TH (2014) Hippocampal volumes in juvenile neuronal ceroid lipofuscinosis: a longitudinal magnetic resonance imaging study. Pediatr Neurol 50:158-163. CrossRef Medline

Usenovic M, Tresse E, Mazzulli JR, Taylor JP, Krainc D (2012) Deficiency of ATP13A2 leads to lysosomal dysfunction, alpha-synuclein accumulation, and neurotoxicity. J Neurosci 32:4240-4246. CrossRef Medline

Vezzani A, Viviani B (2015) Neuromodulatory properties of inflammatory cytokines and their impact on neuronal excitability. Neuropharmacology 96:70-82. CrossRef Medline
Vitiello SP, Benedict JW, Padilla-Lopez S, Pearce DA (2010) Interaction between Sdolp and Btn1p in the Saccharomyces cerevisiae model for Batten disease. Hum Mol Genet 19:931-942. CrossRef Medline

Vitner EB, Farfel-Becker T, Eilam R, Biton I, Futerman AH (2012) Contribution of brain inflammation to neuronal cell death in neuronopathic forms of Gaucher's disease. Brain 135:1724-1735. CrossRef Medline

Westlake VJ, Jolly RD, Bayliss SL, Palmer DN (1995) Immunocytochemical studies in the ceroid-lipofuscinoses (Batten disease) using antibodies to subunit c of mitochondrial ATP synthase. Am J Med Genet 57:177-181. CrossRef Medline

Williams RE, Aberg L, Autti T, Goebel HH, Kohlschütter A, Lönnqvist T (2006) Diagnosis of the neuronal ceroid lipofuscinoses: an update. Biochim Biophys Acta 1762:865-872. CrossRef Medline

Wisniewski KE, Rapin I, Heaney-Kieras J (1988) Clinico-pathological variability in the childhood neuronal ceroid-lipofuscinoses and new observations on glycoprotein abnormalities. Am J Med Genet Suppl 5:27-46. Medline

Xiong J, Kielian T (2013) Microglia in juvenile neuronal ceroid lipofuscinosis are primed toward a pro-inflammatory phenotype. J Neurochem 127: 245-258. CrossRef Medline 